\title{
In silico targeting SARS-CoV-2 spike protein and main protease by biochemical compounds
}

\author{
Laleh Babaeekhou $^{1,2}$ (D) $\cdot$ Maryam Ghane $^{1} \cdot$ Mahdi Abbas-Mohammadi ${ }^{3}$
}

Received: 8 April 2021 / Accepted: 30 July 2021 / Published online: 22 September 2021

(C) Institute of Molecular Biology, Slovak Academy of Sciences 2021

\begin{abstract}
Since there is no general agreement on drug treatment of SARS-CoV-2, the search for a new drug capable of treating COVID-19 is of utmost priority. This study aims to dereplicate the chemical compounds of the methanol extract of Salvia officinalis and Artemisia dracunculus, and assay the inhibitory effect of these compounds as well as the previously dereplicated components of Zingiber officinale against SARS-CoV-2 in an in-silico study. A molecular networking (MN) technique was applied to find the chemical constituents of the extracts. Docking analysis was also used to find the binding affinity of dereplicated components from S. officinalis, A. dracunculus, and Z. officinale to COV-2-SP and $\mathrm{M}^{\text {pro }} .57$ compounds were dereplicated from the MeOH extracts of $S$. officinalis and A. dracunculus which include the class of polyphenols, flavonoids, coumarins, phenylpropanoids, anthocyanins, and dihydrochalcones. Molecular docking analysis indicated a high affinity of about 27 compounds from three mentioned plants against studied targets. kaempferol 3-O-rutinoside, neodiosmin, and querciturone with docking score values of -10.575, -10.208 , and $-9.904 \mathrm{Kcal} / \mathrm{mol}$ and $\mathrm{k}_{\mathrm{i}}$ values of $0.016606,0.030921$, and 0.051749 , respectively were found to have the highest affinities against COV-2-SP. 2-phenylethyl beta-primeveroside, curcumin PE, and kaempferol 3-O-rutinoside also indicated the highest affinity against $\mathrm{M}^{\text {pro }}$ with docking scores of $-10.34,-10.126$ and -9.705 and $\mathrm{k}_{\mathrm{i}}$ values of $0.024726,0.035529$, and 0.072494 , respectively. MN can be successfully used for the dereplication of metabolites from plant extracts. In addition, the in-silico binding energies introduced several inhibitors from Z. officinale, S. officinalis, and A. dracunculus for the treatment of SARS-CoV-2 disease.
\end{abstract}

Keywords S. officinalis $\cdot$ A.dracunculus $\cdot$ Z. officinale $\cdot \mathrm{SARS}-\mathrm{CoV}-2 \cdot$ Spike protein $\cdot \mathrm{M}^{\text {pro }}$

\section{Introduction}

The novel strain of coronavirus (CoV) Which first emerged in Wuhan, China was identified at the end of 2019 (2019-nCoV) (Zhu et al. 2020) and then officially named severe acute respiratory syndrome-related coronavirus (SARS-CoV-2). Different variants of SARS-CoV-2 with different transmission

Laleh Babaeekhou

babaeekhou@iiau.ac.ir

1 Department of Biology, Islamshahr Branch, Islamic Azad University, Islamshahr, Iran

2 Department of Biology-Microbiology, Faculty of Science, Islamshahr branch Islamic Azad University, Sayyad Shirazi St, P.O. Box: 33135/369, Tehran, Iran

3 Department of Organic Chemistry, Faculty of Chemistry, University of Kashan, Kashan, Iran and disease characteristics, and different impact on vaccine efficacy has posed one of the biggest threats to global health. Based on the WHO weekly report on Coronavirus disease 2019 (COVID-19) released on 29 June 2021, the number of confirmed cases and deaths worldwide has reached over 180 million and about 4 million respectively. Alongside tracking the newly emerged variants of the virus, one of the major priorities is the evaluation of existing vaccines for efficacy against variants (WHO organization 2021). Until 1st July $2021,23.4 \%$ of the world population has received at least one dose of each vaccine and in low-income countries, only $0.9 \%$ have received at least one dose (https:// ourworldindata.org). Existing therapies like Remdesivir (Veklury) have failed for the treatment of severe forms of the disease (Goldman et al. 2020) and until widespread and confirmed immunity against COVID-19, prevention of further disease spread and novel therapies are needed (Voysey et al. 2020). So, drug development should progress based on SARS-CoV-2 different molecular targets. 
Coronavirus entry into host cells is initiated by binding the envelope spike glycoprotein to the cell surface receptor angiotensin-converting enzyme 2 (ACE-2) (Dimitrov 2004; Li et al. 2003). S is a class I viral fusion protein (1,300 amino acids) that trimerizes upon its folding. It is composed of two main subunits: S1, in amino, and S2 in the carboxy-terminal. $\mathrm{S} 1$ includes the receptor-binding domain and S2 drives membrane fusion. In most coronaviruses, there is a cleavage site at the joining point of $\mathrm{S} 1$ and $\mathrm{S} 2$ and a proteolytic cleavage happens by host proteases at the $\mathrm{S} 2$ cleavage site (Bosch et al. 2003; Du et al. 2009). But the S1 and S2 subunits are still connected in the pre-fusion form of the $\mathrm{S}$ trimer. After virion attachment to the host cell receptor, a second essential cleavage by endo-lysosomal proteases occurs at the S2' cleavage site, allowing the release of the internal fusion peptide (FP) and fusion of the spike protein envelope into the host membrane and transition of S2 into the post-fusion structure (Burkard et al. 2014; Li 2016). So, in the viral entry process, the spike protein shows two different forms: pre-fusion or the form which is seen on mature virions, and post-fusion which is formed after membrane fusion (Shang et al. 2018; Song et al. 2018; Walls et al. 2016). In previous studies, the potential receptor usage of the SARS-CoV-2 spike protein (COV-2-SP) is analyzed and is shown that the new strain also uses ACE2 as its receptor. This is because the sequence of COV-2-SP receptor-binding domain (RBD) that binds to ACE-2, is similar to that of severe acute respiratory syndrome coronavirus (SARS-CoV). It is also shown that COV-2-SP RBD has improved its binding affinity to human ACE-2 by residue changes at $\mathrm{RBD}$-receptor interaction spots (Shang et al. 2020). These findings make COV-2-SP a potential candidate that can be specifically targeted by entry blocking inhibitor drugs.

In the human coronavirus (RNA positive-stranded) replication cycle, two overlapping polyproteins that are, replicase 1a, and replicase $1 \mathrm{ab}$, are encoded by the $229 \mathrm{E}$ replicase gene (Herold et al. 1993). These proteins continue replication and transcription in the viral replication cycle but for the production of regulatory non-structural polypeptides from polyproteins, a $33.1-\mathrm{kD} \mathrm{HCoV} 229 \mathrm{E}$ main proteinase $\left(\mathrm{M}^{\mathrm{pro}}\right)$ and papain-like protease (PLP) is essential (Thiel et al. 2001; Ziebuhr et al. 1995). Because of the similarity of the cleavage site of $\mathrm{M}^{\text {pro }}$ with picornavirus $3 \mathrm{C}$ proteinases, it's also called 3 C-like proteinase (3CL ${ }^{\text {pro }}$ ) (Anand et al. 2002). The coronavirus $\mathrm{M}^{\text {pro }}$ comprises three structural domains. Domains I (residues 8-99) and II (residues 100-183) are antiparallel $\beta$ barrels representing the chymotrypsin catalytic domain. The substrate-binding site is located in a motif between these two domains. Domain III with five helices is located on the C-terminal of the enzyme (residues 200-300) and contains the proteolytic site. This latter domain is connected to domain II with a long loop (residues 184-199) (Anand et al. 2003; Sirois et al. 2007). There is no human protease similar to the cleavage of $\mathrm{M}^{\text {pro }}$ so it is a suitable target for controlling coronaviruses (Anand et al. 2003).

In our previous study, chemical compounds of Zingiber officinale were identified using Molecular Networking (MN) (Babaeekhou and Ghane 2020). Considering the importance of a combination of in silico and experimental studies in drug discovery, in the present study, an MN technique based on an untargeted MS/MS analysis was used to find the chemical composition of the methanol extracts of $S$. officinalis and A. dracunculus. Then, the molecular docking strategy was applied to dereplicated compounds of $Z$. officinale, $S$. officinalis, and A. dracunculus to evaluate their binding energies with COV-2-SP and $\mathrm{M}^{\text {pro }}$ viral targets. In continue, in this study, the structure of the SARS-CoV-2 chimeric receptor-binding domain complexed with its receptor human ACE2 (PDB: 6VW1) (Shang et al. 2020); pre-fusion 2019-nCoV spike glycoprotein with a single receptor-binding domain up (PDB: 6VSB) (Wrapp et al. 2020); and the crystal structure of COVID-19 $\mathrm{M}^{\text {pro }}$ (PDB IDs 6LU7 and 6M03) (Jin et al. 2020) were selected as viral targets.

\section{Materials and methods}

\section{Plant materials and extraction}

$200 \mathrm{~g}$ of whole plants of S. officinalis and A. dracunculus were powdered and extracted using $200 \mathrm{~mL}$ methanol solvent (three times) via a maceration method. The extracts were then combined and evaporated to dryness under reduced pressure to obtain solvent-less extracts.

\section{Mass spectrometry analysis}

Samples were prepared in methanol at a concentration of 2 $\mathrm{mg} / \mathrm{mL}$ and $5 \mu 1$ were injected for each LC-MS analysis. LC-MS/MS analyses were carried out on a Waters Acquity UPLC system equipped with a Waters Xevo ${ }^{\mathrm{TM}}$ QToF mass spectrometer and an electrospray source. Mass spectrometry (MS) data were acquired simultaneously in the positive mode at a mass range of m/z 1000-1000 Da. Samples were dissolved in methanol at the concentration of $2 \mathrm{mg} / \mathrm{mL}$ and injected into a $5 \mu \mathrm{m}$ SunFire ${ }^{\mathrm{TM}} \mathrm{C}-18$ column $(250 \times 4.6$ $\mathrm{mm}$ ). Two solvents, water $+0.1 \%$ acetic acid (solvent $\mathrm{A}$ ) and methanol $+0.1 \%$ acetic acid (solvent B) were used as the mobile phase at a flow rate of $0.4 \mathrm{~mL} / \mathrm{min}$. The ESI conditions and mass spectrometry acquisition parameters were set as follows: capillary voltage, detector voltage, sampling cone, and extraction cone voltages: $3.0 \mathrm{kV}, 2.2 \mathrm{kV}, 25 \mathrm{~V}$, and $4.0 \mathrm{~V}$ respectively; source and desolvation temperatures: 150 and $250{ }^{\circ} \mathrm{C}$, respectively and cone and desolvation flow: 50 and $600 \mathrm{~L} / \mathrm{h}$, respectively. Eight most intense ions with a threshold 
higher than 50 were selected for data-dependent MS/MS survey scans.

\section{Molecular networking}

The MS/MS data were converted into the mzXML format using MSconvert software for spectral data processing. The mzXML data were uploaded to the Global Natural Products Social (GNPS) MN web server (http://gnps.ucsd.edu) and analyzed using the MN workflow. MS/MS spectra were filtered by choosing only the top 6 fragment ions in the +/- 50Da window throughout the spectrum. Then, to create consensus spectra, a diversity of parameters such as precursor ion mass tolerance (0.2 Da), MS/MS fragment ion tolerance (0.08 Da), minimum cosine score (0.6), and minimum matched fragment ions (4 peaks) were applied. When each of the nodes appeared in each other's respective top 10 most similar nodes, edges between two nodes were kept in the network. Then, the spectra in the network were searched against GNPS' spectral libraries. Cytoscape 2.8.3 was also carried out to visualize the data as a network of nodes and edges.

\section{Molecular docking study}

Preparation of ligands and targeted enzymes, as well as the molecular docking analysis, was accomplished on the Glide of Schrodinger package 2016-2 (Vasavi et al. 2017). The structure of COV-2-SP and $\mathrm{M}^{\text {pro }}$ were taken from Protein Data Bank (PDB). They were as follows: prefusion 2019-nCoV spike glycoprotein with a single receptor-binding domain up (PDB ID: 6VSB); 2019-nCoV chimeric receptor-binding domain complexed with its receptor human ACE2 (PDB ID: 6VW1); COVID-19 main protease in the apo form (PDB ID: 6M03) and COVID-19 main protease complex with an inhibitor N3 (PDB ID: 6LU7). Nelfinavir and Lopinavir were used as interaction assessment indicators. All protein structures were prepared on protein preparation wizard in Maestro by removing the crystallized ligands, all free water molecules, and complexed proteins with targets in PDB such as human ACE2 and inhibitor N3 chains. Then energy minimization was done. The grid box of enzymes was created with a Grid generation application at particular residues of the proteins obtained from the DEPTH server. The chemical structures of ligands were drawn on ChemDraw Professional 15.0 and conformationally optimized on the LigPrep module of Maestro. Docking analysis was performed with the flexible ligand docking at an "extra precision" level. Docking scores were then used to obtain the predicted inhibition constants $\left(\mathrm{K}_{\mathrm{i}}\right)$ via the formula: $\mathrm{K}_{\mathrm{i}}=\exp ^{(\Delta \mathrm{G} / \mathrm{RT})}$, where $\Delta \mathrm{G}$ is the binding energy, $\mathrm{R}$ is the universal gas constant $\left(1.98 \mathrm{cal} \mathrm{mol}^{-1} \mathrm{~K}^{-1}\right)$ and $\mathrm{T}$ is the temperature $(298.15 \mathrm{~K})$. Finally, RMSD values were determined to compare the docked conformation of ligands with the nelfinavir conformation as a positive control.

\section{Results}

\section{S. officinalis and A. dracunculus compounds}

Metabolite profiling of S. officinalis and A. dracunculus was determined by UHPLC-HRMS/MS. To perform dereplication, the HPLC analytical conditions were initially optimized for both extracts before LC-MS and MS/MS analyses. Acquired MS/MS spectra of both extracts in the positive mode were used to generate a network for the visualization process of dereplicated constituents in an optimum manner. Analysis of the MS/MS data of S. officinalis gave rise to the identification of 637 parent ions, which were visualized as nodes in a molecular network, forming 117 clusters ranging from one to 86 connected nodes (Fig. 1). Then, analysis of the generated network against the GNPS library resulted in annotation of thirty-seven constituents (Table 1) The most abundant compounds of this network were included in the flavonoids. Eleven glycosylated flavonoids, six un-glycosylated flavonoids, and two glycosylated anthocyanins, members of the flavonoid group of phytochemicals, were annotated. Phenyl propanoids ( 7 Compd.) were also identified to be the other major class of dereplicated compounds (Fig. 2; Table 1).

The molecular networking evaluation revealed 538 parent ions for the MS/MS data of A. dracunculus, forming 61 clusters ranging from one to 43 connected nodes (Fig. 1). Molecular networking analysis of the network of A. dracunculus against the GNPS library afforded to the tentative annotation of 20 compounds (Table 2). Flavonoids (7 compounds), coumarins (6 compounds) phenylpropanoids (5 compounds), and dihydrochalcones ( 2 compounds) were the class of dereplicated compounds. The structure of dereplicated compounds has been shown in Fig. 3.

\section{Binding energies of the ligands against target proteins}

Docking analysis was done to assess the binding energies and interaction modes of the dereplicated ligands from S. officinalis and A. dracunculus, and Z. officinale (obtained in our previous study (Babaeekhou and Ghane 2020), against target proteins 6VW1, 6VSB (COV-2-SP), 6LU7, and 6M03 $\left(\mathrm{M}^{\mathrm{pro}}\right)$ using Schrodinger package. The output of the docking analysis is shown in Table 3.

To validate docking analyses, a standard ligand of each enzyme in co-crystallized complexes e.g. N3 peptide inhibitor from the $\mathrm{M}^{\text {pro }}$ was removed and re-docked into the active site of the related enzyme. The same protocol such as the grid parameters and the precision level were employed in the process. It was performed to ensure the inhibitor binds exactly to the active site cleft. The superimposed analysis revealed less deviation of the re-docked complex in comparison to the actual co-crystallized complex (Table 4). In addition, Fig. 4 

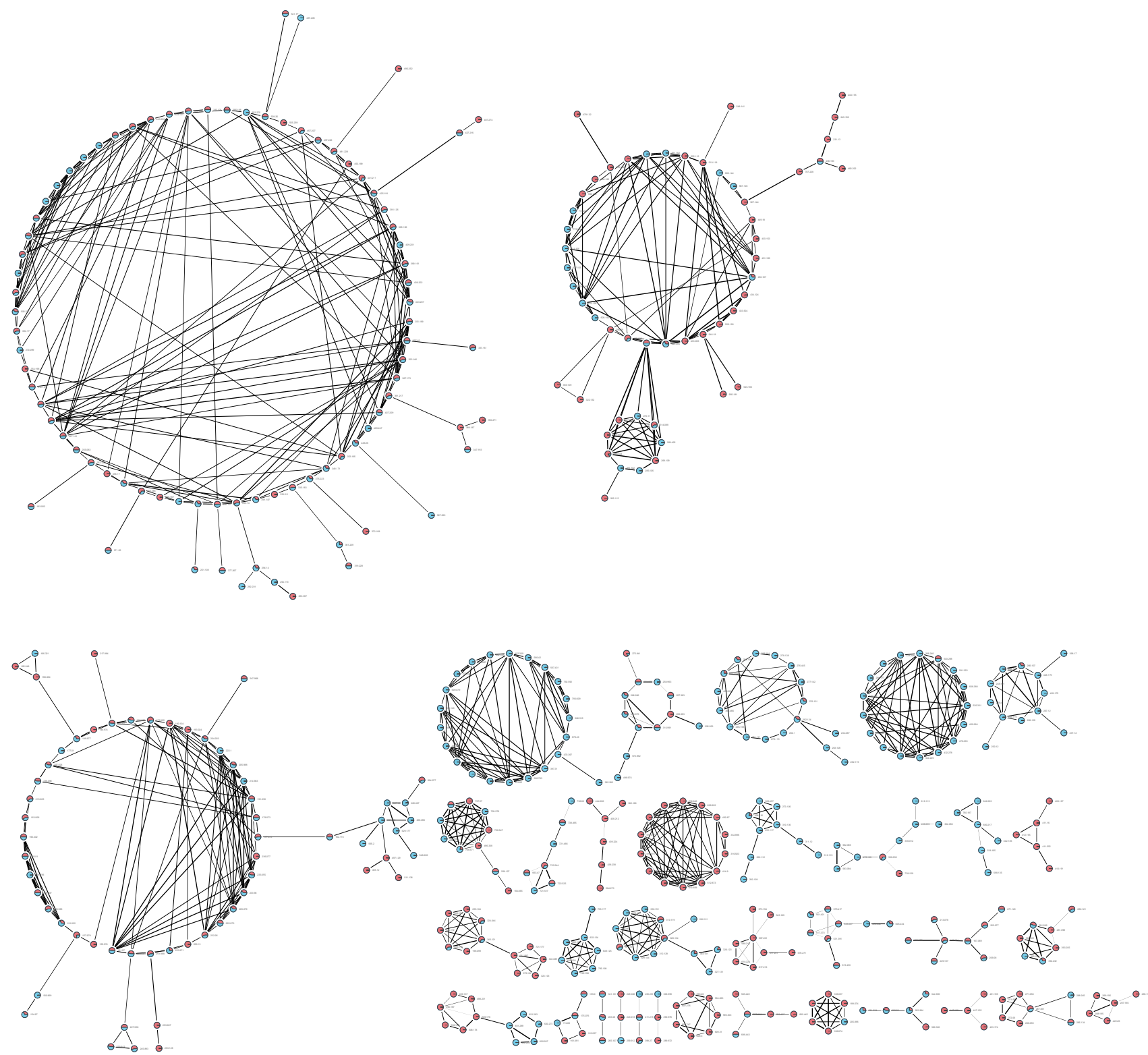

i>

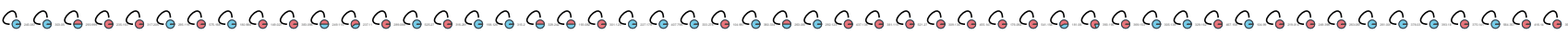

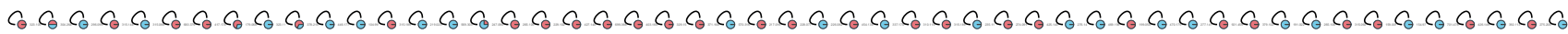

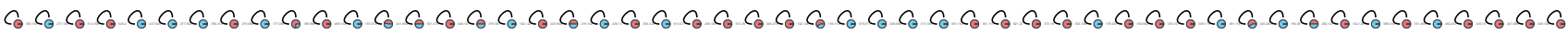

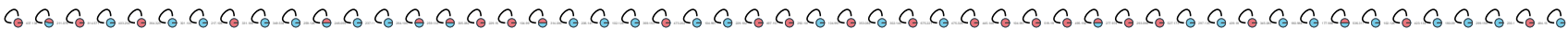

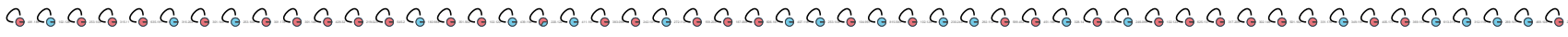

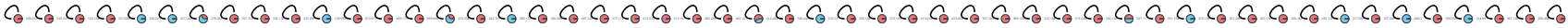

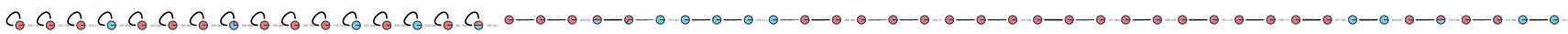

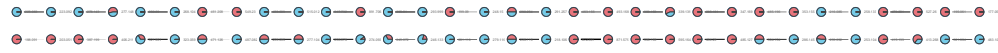

Fig. 1 The molecular network Methanolic extracts of S. officinalis and A. dracunculus with a cosine similarity score cut off of 0.60

indicates the superimposed form of all docked ligands in the active site of four evaluated targets.

Based on the obtained results, the highest binding energy with COV-2-SP (6VW1) was observed for kaempferol 3-O-rutinoside (SO-36) and neodiosmin (SO-37) compounds from $S$. officinalis extract, followed by chicoric acid (AD-17), querciturone (AD-18) from A. dracunculus and 3-[4,5-dihydroxy-6-(hydroxymethyl)-3-[3,4,5-trihydroxyoxan-2-yl] oxyoxan-2-yl] oxy - 2- (3,4-dihydroxyphenyl)5-hydroxy-7-methoxy chromen-4-one (ZO-13) and sissostrin (ZO-40) from $Z$. officinale with docking values(Ki) of $-10.575(0.017)$ and -10.208 (0.031), -9.457 (0.110), -9.256 


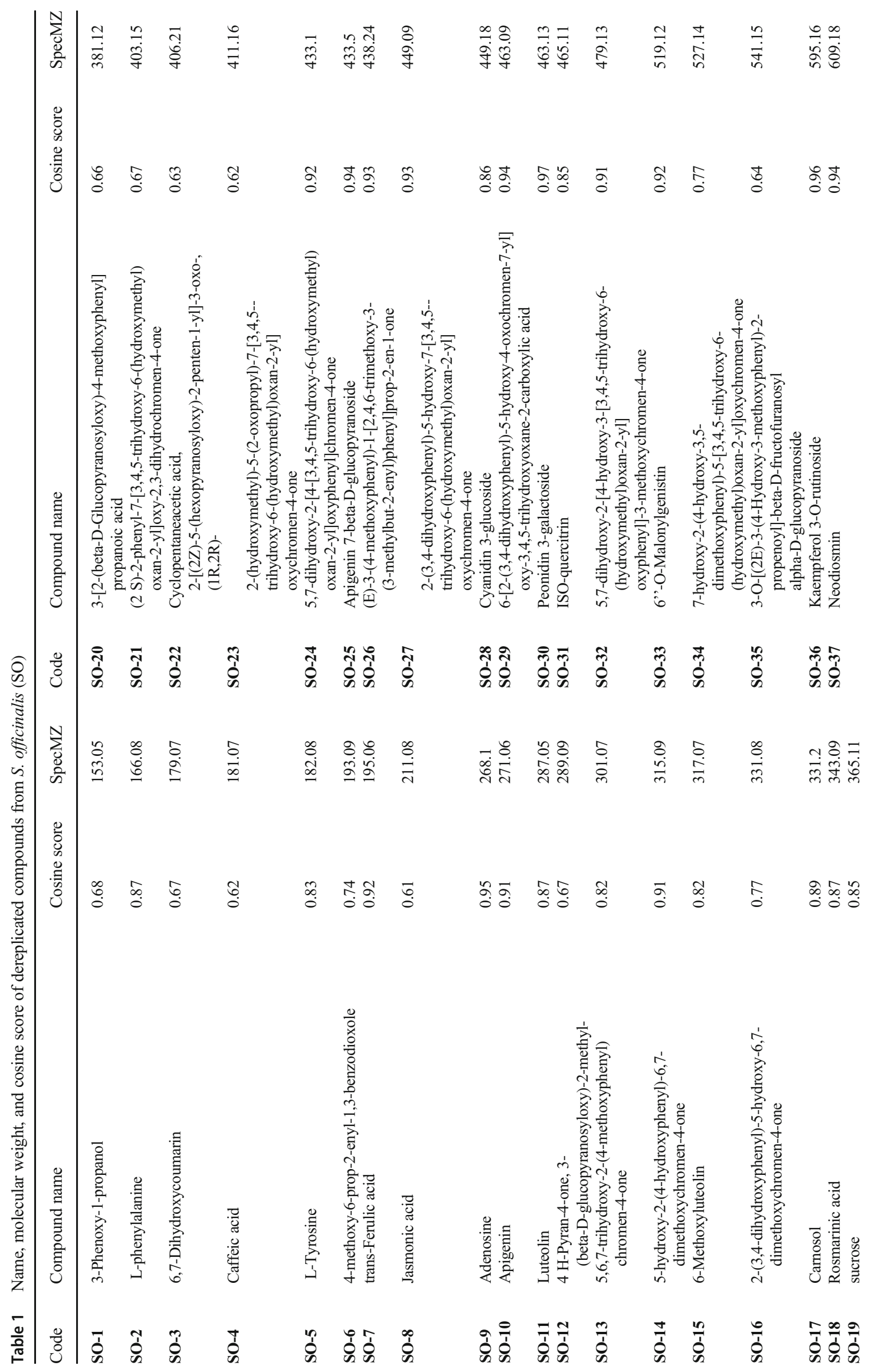



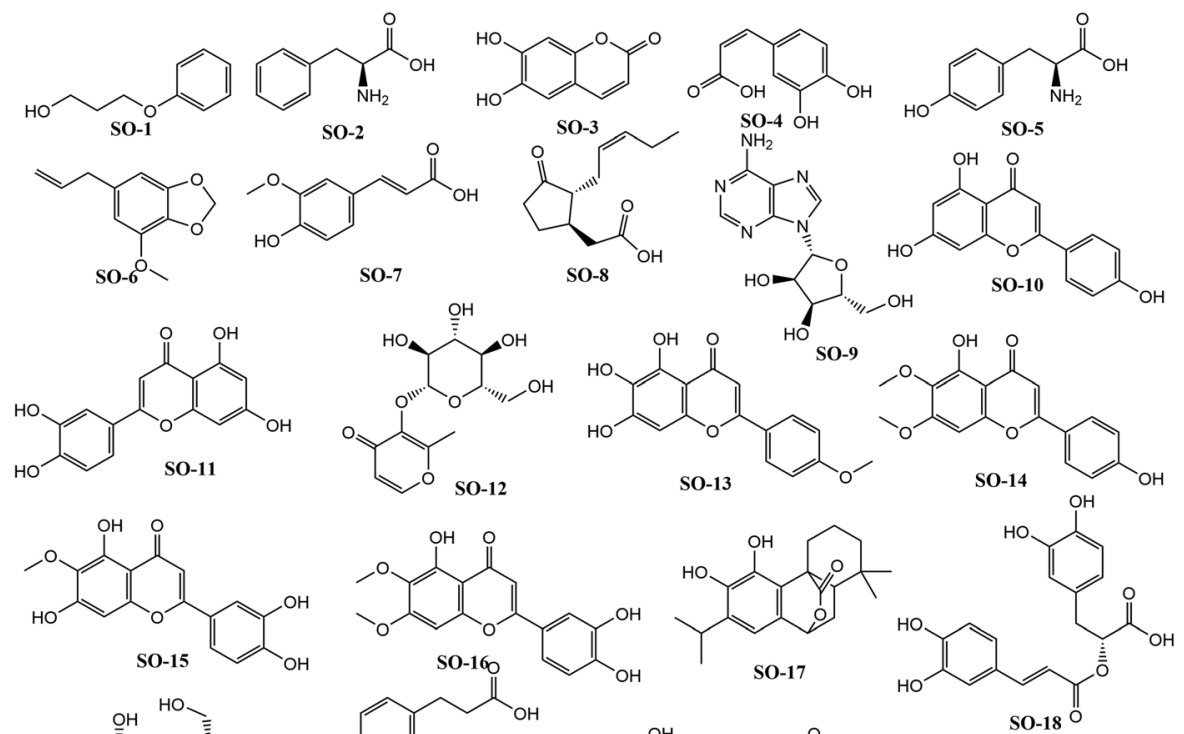<smiles>C=C(O)CCc1ccc(OC)cc1O[C@@H]1O[C@H](CO)[C@@H](O)[C@H](O)[C@H]1O</smiles><smiles>CC(=O)Cc1cc(O[C@@H]2O[C@H](CO)[C@@H](O)[C@H](O)[C@H]2O)cc2oc(CO)cc(=O)c12</smiles><smiles>COc1ccc(/C=C/C(=O)c2c(/C=C/c3ccc(OC)c(OC)c3)c(OC)c(CC=C(C)C)c(CC=C(C)C)c2OC)cc1O</smiles>

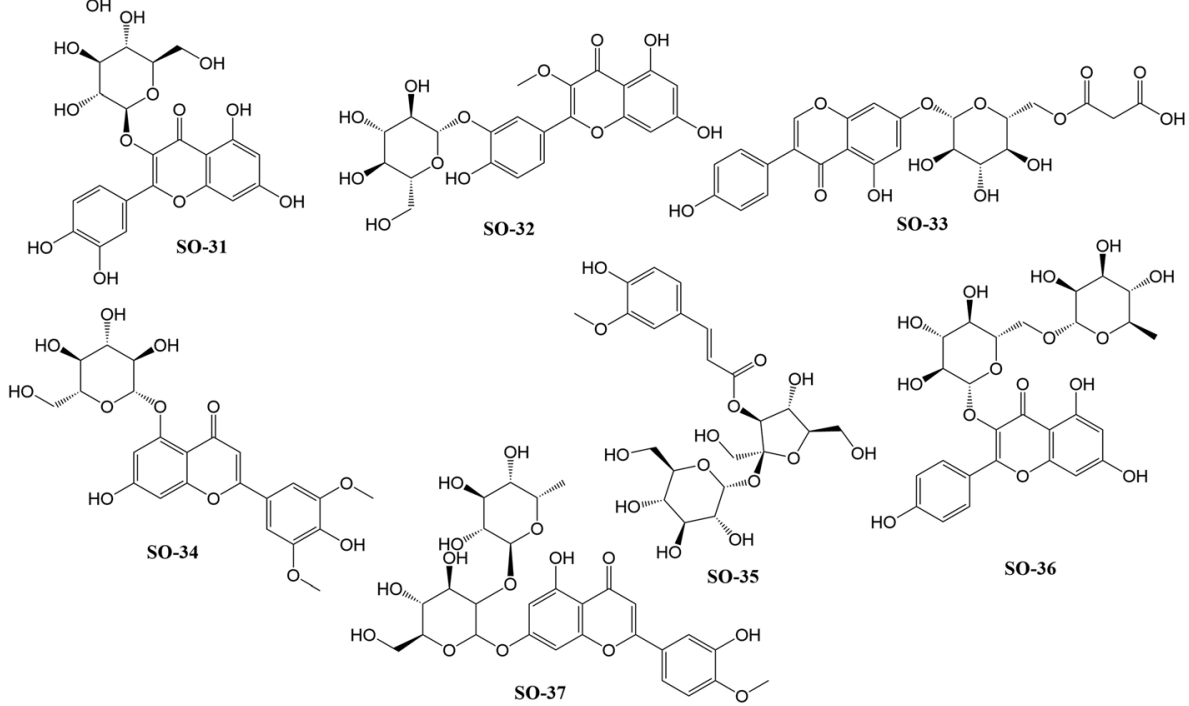

Fig. 2 Chemical structure of dereplicated compounds from S. officinalis (SO) 
Table 2 Name, molecular weight, and cosine score of dereplicated compounds from A. dracunculus (AD)

\begin{tabular}{|c|c|c|c|c|c|c|c|}
\hline Code & Compound name & Cosine score & SpecMZ & Code & Compound & Cosine score & SpecMZ \\
\hline AD-1 & Umbelliferone & 0.65 & 163.16 & AD-11 & Kaempferol & 0.78 & 287.07 \\
\hline AD-2 & L-phenylalanine & 0.87 & 166.08 & AD-12 & Sakuranetin & 0.8 & 287.11 \\
\hline AD-3 & Aesculetin & 75 & 179.15 & AD-13 & Quercetin & 0.86 & 303.02 \\
\hline AD-4 & Caffeic acid & 0.72 & 181.07 & AD-14 & Quercetagetin & 0.81 & 319.25 \\
\hline AD-5 & Scopoletin & 0.7 & 193.2 & AD-15 & Chlorogenic acid & 0.7 & 377.1 \\
\hline AD-6 & 8-Hydroxyartemidin & 0.68 & 217.27 & AD-16 & 2-Phenylethyl beta-primeveroside & 0.67 & 416.17 \\
\hline AD-7 & Artemidin & 0.82 & 201.26 & AD-17 & Chicoric acid & 0.75 & 457.35 \\
\hline AD-8 & Artemidiol & 0.69 & 217.27 & AD-18 & Querciturone & 0.87 & 479.08 \\
\hline AD-9 & Davidigenin & 0.77 & 259.28 & AD-19 & Estragonoside & 0.73 & 479.43 \\
\hline AD-10 & 4-O-Methyl davidigenin & 0.84 & 273.29 & AD-20 & Isorhamnetin 3-glucuronide & 0.84 & 493.1 \\
\hline
\end{tabular}

(0.155), -9.27 (0.151) and - $8.643(0.438) \mathrm{kcal} / \mathrm{mol}(\mu \mathrm{M})$, respectively (Table 3 , Supplementary data). The highest affinity score with the $\mathrm{M}^{\text {pro }}(6 \mathrm{M} 03)$ was observed for polyhydroxylated compounds: 2-phenyl ethyl beta-primeveroside (AD-16), 3-O-[3-(4-hydroxy-3-methoxy phenyl)-2-propenoyl]-beta-D-fructofuranosyl alpha-Dglucopyranoside (SO-35) and curcumin PE (ZO-43) from three studied plants with docking energies $(\mathrm{Ki})$ of -10.34 $(0.025),-10.232(0.029)$ and $-10.126(0.035) \mathrm{kcal} / \mathrm{mol}(\mu \mathrm{M})$, respectively. Docking results of the 6VSB target indicated that the docking scores were the highest for a flavonoid from Z. officinale (ZO-13) with a docking score (Ki) of -9.96 (0.047) $\mathrm{kcal} / \mathrm{mol}(\mu \mathrm{M})$ followed by two other flavonoids from tarragon and $S$. officinalis including querciturone or Quercetin 3-O-glucuronide (AD-18) with -9.904 (0.052) $\mathrm{kcal} / \mathrm{mol}(\mu \mathrm{M})$ and 2-(3,4-dihydroxy phenyl)-5-hydroxy-7-[3,4,5-trihydroxy-6-(hydroxyl methyl)oxan-2-yl] oxychromen-4-one (SO-27) with - 9.562 (0.092) $\mathrm{kcal} / \mathrm{mol}(\mu \mathrm{M})$. The flavonoid sissostrin (ZO-40) with a docking score (Ki) of -9.399 (0.122) $\mathrm{kcal} / \mathrm{mol}$ $(\mu \mathrm{M})$, the phenylpropanoid chicoric acid (AD-17) with a docking score $(\mathrm{Ki})$ of $-8.905(0.281) \mathrm{kcal} / \mathrm{mol}(\mu \mathrm{M})$, and 3-O-[3-(4-hydroxy-3-methoxy phenyl)-2-propenoyl]beta-D-fructofuranosyl alpha-D-glucopyranoside (SO-35) with a docking score $(\mathrm{Ki})$ of $-8.272(0.821) \mathrm{kcal} / \mathrm{mol}$ $(\mu \mathrm{M})$ from three evaluated species indicated the best affinity to the 6LU7 target.

The major interactions between the high potentially active ligands and the active site of proteins were observed to be the $\mathrm{H}$-bond interaction of the hydroxyl groups and ion-bonds as well as $\pi-\pi$ stacking of the aromatic rings with the enzyme (Table 5). Regarding 6VSB which is consists of three chains and 1288 residues, a high number of $\mathrm{H}$-bonds is observed between ligands and amino acids. Furthermore, binding interaction profiles of some active ligands against the $\mathrm{M}^{\text {pro }}$ and COV-2-SP targets are indicated in Figs. 5 and 6.

\section{Discussion}

Several studies have reported the biochemical composition of S. officinalis extract. Lima et al. (2007) evaluated the plant water and methanolic extracts for the presence of phenolic compounds using HPLC/DAD and detected 5 phenolic acids and 3 flavonoids. In a similar study, using HPLC-UV/VIS polyphenolic profile of the $S$. officinalis was identified for 14 compounds, and analysis of phytochemical compounds of the plant by HPLC-DAD-MSD revealed different phytochemical compounds of the plant including phenolic acids (9 compounds), flavonoids (3 compounds), phytosterols ( 2 compounds), saponins (6 compounds), and alkaloids ( 5 compounds) (Hernández-Saavedra et al. 2016). In the above-mentioned studies, rosmarinic acid, caffeic acid, luteolin-7-glucoside, chlorogenic acid, epicatechin, ellagic acid, quercetin were the major identified compounds. Using $\mathrm{MN}$ technique in the present study a wide range of components including polyphenols, alkaloids, flavonoids, terpenoids, anthraquinones, glycosides, and steroids were dereplicated and identification of some common compounds like caffeic acid, rosmarinic acid, luteolin, and quercetin in addition to 33 other compounds showed MN is an applicable and sensitive technique for chemical composition identification. The same scenario applies to the A. dracunculus and some similar compounds to the present study have been reported from previous studies (Duric et al. 2015; Mumivand et al. 2017) which confirms the accuracy of the applied technique. In the Mumivand et al. study major phenolic and flavonoid compounds of 12 Iranian A. dracunculus extracts were identified by RP-HPLC which resulted in the detection of chlorogenic, syringic, and caffeic acids and the predominant flavonoid was quercetin. It is worth mentioning that there are some identified compounds for $S$. officinalis and A. dracunculus which are reported for the first time in this study (Tables 1 and 2). 
<smiles>O=c1ccc2ccc(O)cc2o1</smiles>

AD-1<smiles>N[C@@H](Cc1ccccc1)C(=O)O</smiles>

AD-2<smiles>O=c1ccc2cc(O)c(O)cc2o1</smiles>

AD-3<smiles>O=C(O)/C=C/c1ccc(O)c(O)c1</smiles>

AD-4<smiles>COc1cc2ccc(=O)oc2cc1O</smiles>

AD-5<smiles>CC/C=C/c1cc2cccc(O)c2oc1=O</smiles>

AD-6<smiles>CC/C=C/c1cc2ccccc2oc1=O</smiles>
AD-7<smiles>COc1ccc(CCC(=O)c2ccc(Cl)cc2O)cc1</smiles>

AD-14

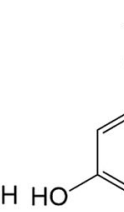<smiles>CCC(O)C(O)c1cc2ccccc2oc1=O</smiles>

AD-8 OH<smiles>O=C(CCc1ccc(O)cc1)c1ccc(O)cc1O</smiles>

AD-9

\author{
AD-9
}<smiles>C1CCCC1</smiles><smiles>O=C(O)/C=C/c1ccc(O)c(O)c1</smiles>

AD-15<smiles>CCCc1ccccc1</smiles><smiles>O=C(O)[C@H]1OC(Oc2c(-c3ccc(O)c(O)c3)oc3cc(O)cc(O)c3c2=O)[C@H](O)[C@@H](O)[C@H]1O</smiles><smiles>Cc1ccc(O)c(O)c1</smiles><smiles>CCC(=O)O</smiles><smiles>COc1cc(-c2cc(=O)c3c(O)c(O)c(O)c(OC4OC(C)C(O)C(O)C4O)c3o2)ccc1O</smiles><smiles>COc1cc(-c2oc3cc(O)cc(O)c3c(=O)c2OC2OC(C(=O)O)C(O)C(O)C2O)ccc1O</smiles>

Fig. 3 Chemical structure of dereplicated compounds from A. dracunculus (AD)

By targeting viral proteins in in-silico studies, we can rapidly screen plant compounds and make a shortlist of drug candidates. This helps to meet the immediate demand for an effective treatment against the 2019-nCOV infection. Therefore, in this study, we have performed a docking analysis on 104 yielded plant compounds to reach a list of potential candidates for future in vitro/vivo investigations. In this study, COV-2-SP and $\mathrm{M}^{\text {pro }}$ viral potential targets were chosen for the assessment of affinity of 3 plant compounds including Z. officinale, reported in our previous study (Babaeekhou and Ghane 2020), S. officinalis, and A. dracunculus. In this present study several dereplicated compounds showed strong interaction with 6VW1 and 6VSB (COV-2-SP) including 3-[(2 S,3R,4 S,5 S,6R)_4,5-dihydroxy-6-(hydroxymethyl) _3-[(2 S,3R,4 S,5R)_3,4,5-rihydroxyoxan-2-yl] oxyoxan-2-yl] oxy-2-(3,4- dihydroxyphenyl)_5-hydroxy-7- methoxychromen-4-one (ZO-13), sissostrin (ZO-40), luteolin (ZO-41), uridine (ZO-45), curcumin PE (ZO-43), [5-acetyloxy-1,7-bis(3,4 dihydroxyphenyl)heptan-3-yl] acetate (ZO-25) from $Z$. officinale, SO-36, SO-37, SO-31, SO-27, SO-28, SO-35, SO-29, SO-32, SO-25, SO-22, SO-20 from $S$. officinalis, and AD-17, AD-18, AD-20, AD-14, AD-19, AD-16, AD-15 from A. dracunculus (Table 3).

Extensive research on the cell entry mechanisms of coronaviruses shows that different domains of COV-2-SP are participating in receptor binding and fusion. It is suggested that the receptor-binding domain plays a binary role in coronavirus entry including viral attachment to the host receptor and the fusion of the viral envelope with the cellular membrane (Shang et al. 2020). In this study, based on the proposed detailed structure of mouse hepatitis coronavirus (MHV) 
Table 3 Molecular docking analysis of chemical compounds against COV-2-SP and $\mathrm{M}^{\text {pro }}$

\begin{tabular}{|c|c|c|c|c|c|c|c|c|c|}
\hline \multirow[t]{3}{*}{ Compound code } & \multicolumn{4}{|c|}{ Docking score $(\mathrm{kcal} / \mathrm{mol})$} & \multirow[t]{3}{*}{ Compound code } & \multicolumn{4}{|c|}{ Docking score $(\mathrm{kcal} / \mathrm{mol})$} \\
\hline & \multicolumn{2}{|c|}{ COV-2-SP } & \multicolumn{2}{|l|}{$\mathrm{M}^{\text {pro }}$} & & \multicolumn{2}{|c|}{ COV-2-SP } & \multicolumn{2}{|l|}{$\mathrm{M}^{\text {pro }}$} \\
\hline & 6VW1 & $6 \mathrm{VSB}$ & 6LU7 & $6 \mathrm{M} 03$ & & 6VW1 & $6 \mathrm{VSB}$ & 6LU7 & $6 \mathrm{M} 03$ \\
\hline $\mathrm{ZO}-1$ & -3.82 & -6.603 & -3.467 & -3.619 & $\mathrm{ZO}-25$ & -5.733 & -8.72 & -8.551 & -7.724 \\
\hline $\mathrm{ZO}-2$ & -3.955 & -4.649 & -4.195 & -4.684 & ZO-26 & -5.887 & -4.097 & -3.928 & -3.849 \\
\hline $\mathrm{ZO}-3$ & -2.003 & -4.022 & -3.339 & -4.421 & $\mathrm{ZO}-27$ & -3.511 & -2.983 & -2.683 & -3.818 \\
\hline $\mathrm{ZO}-4$ & -4.787 & -5.573 & -4.701 & -5.848 & $\mathrm{ZO}-28$ & -4.675 & -3.952 & -3.499 & -3.324 \\
\hline $\mathrm{ZO}-5$ & -4.299 & -4.528 & -3.854 & -4.464 & ZO-29 & -3.639 & -4.272 & -3.579 & -4.607 \\
\hline ZO-6 & -4.327 & -4.442 & -4.972 & -5.323 & ZO-30 & -4.36 & -5.888 & -3.065 & -5.132 \\
\hline $\mathrm{ZO}-7$ & -5.152 & -5.902 & -3.626 & -4.014 & ZO-31 & -7.407 & -8.039 & -8.222 & -8.036 \\
\hline ZO-8 & -4.998 & -5.785 & -5.218 & -5.965 & ZO-32 & -3.633 & -4.73 & -2.301 & -5.445 \\
\hline ZO-9 & -3.646 & -4.828 & -3.568 & -5.321 & ZO-33 & -3.408 & -4.589 & -2.074 & -4.021 \\
\hline ZO-10 & -5.104 & -5.729 & -5.043 & -4.687 & ZO-34 & -6.999 & -7.217 & -5.387 & -7.472 \\
\hline ZO-11 & -4.237 & -3.141 & -4.182 & -4.789 & ZO-35 & -4.355 & -5.543 & -3.736 & -3.369 \\
\hline ZO-12 & -4.309 & -5.43 & -2.378 & -3.973 & ZO-36 & -3.734 & -3.07 & -3.904 & -3.508 \\
\hline ZO-13 & -9.27 & -9.96 & -7.712 & -8.449 & ZO-37 & -4.806 & -6.599 & -3.99 & -3.963 \\
\hline ZO-14 & -4.203 & -3.759 & -4.06 & -4.428 & ZO-38 & -5.802 & -6.979 & -4.785 & -4.075 \\
\hline ZO-15 & -3.14 & -3.069 & -3.653 & -4.026 & ZO-39 & -6.473 & -5.37 & -6.64 & -6.588 \\
\hline ZO-16 & -3.84 & -6.722 & -4.94 & -3.796 & ZO-40 & -8.643 & -9.178 & -9.399 & -8.135 \\
\hline ZO-17 & -3.03 & -2.885 & -3.228 & -4.445 & ZO-41 & -8.081 & -5.89 & -6.2 & -6.503 \\
\hline ZO-18 & -5.172 & -5.235 & -2.082 & -5.838 & ZO-42 & -6.033 & -5.448 & -4.822 & -6.154 \\
\hline ZO-19 & -5.172 & -5.235 & -2.082 & -5.838 & ZO-43 & -7.013 & -8.216 & -6.637 & -10.126 \\
\hline ZO-20 & -4.872 & -6.307 & -4.862 & -7.592 & ZO-44 & -3.503 & -6.192 & -6.207 & -4.661 \\
\hline ZO-21 & -5.504 & -7.097 & -4.616 & -5.225 & ZO-45 & -7.15 & -9.23 & -6.478 & -7.007 \\
\hline ZO-22 & -3.57 & -3.591 & -3.122 & -4.855 & ZO-46 & -4.611 & -4.072 & -4.847 & -6.065 \\
\hline ZO-23 & -6.064 & -7.392 & -5.536 & -7.24 & ZO-47 & -4.069 & -4.961 & -3.438 & -4.211 \\
\hline ZO-24 & -4.33 & -3.24 & -3.956 & -4.112 & & & & & \\
\hline SO-1 & -4.142 & -2.358 & -3.901 & -3.942 & SO-20 & -6.773 & $\mathbf{- 8 . 0 6 7}$ & -6.547 & -9.198 \\
\hline SO-2 & -4.198 & -4.953 & -4.756 & -4.447 & SO-21 & -6.223 & -7.643 & -5.551 & -6.649 \\
\hline SO-3 & -4.667 & -5.281 & -4.915 & -5.377 & SO-22 & -6.994 & -8.102 & -6.449 & -7.06 \\
\hline SO-4 & -5.376 & -4.432 & -4.636 & -6.09 & SO-23 & -4.475 & -7.795 & -6.674 & -8.195 \\
\hline SO-5 & -4.91 & -2.107 & -5.058 & -4.478 & SO-24 & -5.946 & -6.22 & -5.215 & -5.125 \\
\hline SO-6 & -3.448 & -3.618 & -2.274 & -3.443 & SO-25 & -7.481 & -8.808 & -3.525 & -6.242 \\
\hline SO-7 & -4.839 & -4.254 & -4.953 & -5.998 & SO-26 & -4.132 & -4.882 & -2.373 & -3.666 \\
\hline SO-8 & -3.913 & -3.852 & -3.625 & -5.589 & SO-27 & -8.664 & -9.562 & -6.652 & -7.969 \\
\hline SO-9 & -4.359 & -4.886 & -4.595 & -6.462 & SO-28 & -8.582 & -9.143 & -6.508 & -7.142 \\
\hline SO-10 & -5.712 & -4.397 & -3.534 & -6.015 & SO-29 & -7.981 & -7.968 & -6.059 & -8.806 \\
\hline SO-11 & -6.039 & -5.453 & -4.827 & -6.16 & SO-30 & -8.093 & -9.158 & -5.81 & -4.808 \\
\hline SO-12 & -5.408 & -5.817 & -6.408 & -7.148 & SO-31 & -9.517 & -9.43 & -6.264 & -9.23 \\
\hline SO-13 & -4.465 & -6.156 & -4.035 & -7.21 & SO-32 & -7.98 & -7.434 & -7.364 & -7.951 \\
\hline SO-14 & -4.206 & -4.893 & -4.323 & -6.174 & SO-33 & -6.839 & -3.864 & -5.425 & -8.102 \\
\hline SO-15 & -6.288 & -6.944 & -7.055 & -6.928 & SO-34 & -6.177 & -5.664 & -5.324 & -8.183 \\
\hline SO-16 & -4.403 & -5.779 & -5.459 & -5.836 & SO-35 & $\mathbf{- 8 . 5 4 7}$ & -8.762 & -8.272 & -10.232 \\
\hline SO-17 & -4.75 & -4.466 & -3.508 & -5.413 & SO-36 & -10.575 & -8.943 & -7.569 & -9.705 \\
\hline SO-18 & -6.409 & -7.846 & -7.148 & -8.95 & SO-37 & -10.208 & -9.144 & -6.864 & -8.459 \\
\hline SO-19 & -7.424 & -7.86 & -8.247 & -9.351 & & & & & \\
\hline AD-1 & -3.859 & -4.227 & -3.896 & -3.854 & AD-11 & -4.454 & -4.516 & -4.821 & -6.882 \\
\hline AD-2 & -3.933 & -5.666 & -4.669 & -4.067 & $\mathrm{AD}-12$ & -4.126 & -5.269 & -4.41 & -5.561 \\
\hline
\end{tabular}


Table 3 (continued)

\begin{tabular}{|c|c|c|c|c|c|c|c|c|c|}
\hline \multirow[t]{3}{*}{ Compound code } & \multicolumn{4}{|c|}{ Docking score (kcal/mol) } & \multirow[t]{3}{*}{ Compound code } & \multicolumn{4}{|c|}{ Docking score $(\mathrm{kcal} / \mathrm{mol})$} \\
\hline & \multicolumn{2}{|c|}{ COV-2-SP } & \multicolumn{2}{|l|}{$\mathrm{M}^{\text {pro }}$} & & \multicolumn{2}{|c|}{ COV-2-SP } & \multicolumn{2}{|l|}{$\mathrm{M}^{\text {pro }}$} \\
\hline & 6VW1 & 6VSB & 6LU7 & $6 \mathrm{M} 03$ & & 6VW1 & $6 \mathrm{VSB}$ & 6LU7 & $6 \mathrm{M} 03$ \\
\hline AD-3 & -4.667 & -5.281 & -4.915 & -5.377 & $\mathrm{AD}-13$ & -7.279 & -5.975 & -5.75 & -6.981 \\
\hline $\mathrm{AD}-4$ & -5.116 & -5.278 & -4.38 & -5.46 & AD-14 & -8.396 & -6.994 & -6.049 & -8.11 \\
\hline AD-5 & -4.4 & -3.392 & -3.894 & -5.063 & $\mathrm{AD}-15$ & -7.021 & -9.276 & -7.456 & -7.878 \\
\hline AD-6 & -3.304 & -3.749 & -3.555 & -5.2 & AD-16 & -7.291 & -8.609 & -7.777 & -10.34 \\
\hline $\mathrm{AD}-7$ & -3.854 & -3.535 & -2.893 & -4.41 & $\mathrm{AD}-17$ & -9.457 & -9.018 & -8.905 & -8.618 \\
\hline AD-8 & -5.516 & -5.501 & -4.577 & -5.511 & AD-18 & -9.256 & -9.904 & -6.933 & -9.53 \\
\hline AD-9 & -4.58 & -5.392 & -4.589 & -6.323 & AD-19 & -8.087 & -7.095 & -6.561 & -9.599 \\
\hline AD-10 & -4.275 & -5.201 & -5.112 & -6.187 & $\mathrm{AD}-20$ & -8.653 & -8.49 & -6.007 & -8.228 \\
\hline Lopinavir & -5.768 & -7.871 & -3.264 & -6.374 & Nelfinavir & -5.598 & -6.061 & -5.136 & -5.476 \\
\hline
\end{tabular}

Bold values signify high docking scores

spike protein and the amino acid numbering for spike protein domains (Shang et al. 2020; Walls et al. 2016; Walls et al. 2017), the major interactions between active ligands (high docking score) and the spike protein amino acids were assessed. 4 compounds from $Z$. officinale (ZO-13, ZO-31, ZO-40, ZO-41), 10 from S. officinalis (SO-18, SO-27, SO-28, SO-29, SO-30, SO-31, SO-32, SO-35, SO-36, SO-37) and 7 from $A$. dracunculus (AD-13 to AD-15, AD-17 to AD-20) with high docking scores formed H-bonds, pi-pi interactions, and ion-bonds with amino acids 369-379 of 6VW1 (located on RBD of spike protein) (Table 5; Fig. 5). So the inhibitory action of the above-mentioned compounds against the binding of COV-2-SP to its receptor can be proposed in this study. Analysis of the ligand interaction with 6VSB A, B, and $\mathrm{C}$ chains showed that 6 compounds from $Z$. officinale (ZO-13, ZO-25, ZO-3, ZO-40, ZO-43, ZO-45), 13 from $S$. officinalis (SO-18, SO-19, SO-20, SO-22, SO-25, SO-27, SO-28, SO-29, SO-30, SO-31, SO-35, SO-36, SO-37), and 7 compounds from $A$. dracunculus (AD-14 to AD-20) have made $\mathrm{H}$-bonds, pi-pi interactions and ion-bonds with residues located in the RBD (326-572), fusion peptide (amino acids 864 947, buried inside the pre-fusion structure) and S2' cleavage site of the spike protein (Shang, Ye, et al. 2020; Walls et al. 2016; Walls et al. 2017) (Table 5; Fig. 5). So, we can assume that these plant compounds have the potential to inhibit COV-2-SP attachment, proteolysis of S2'site, the transition of the spike protein to the post-fusion conformation, and the fusion of the virions. Antiviral activity of Artemisia annua against SARS-CoV is shown by Li et al. (2005). In this study ethanol extracts of the plant could inhibit Vero E6 cells infection by Two strains of SARS-CoV (BJ001, BJ006). Also, Dihydrotanshinone, a lipophilic compound from Salvia miltiorrhiza is shown to have inhibitory activity toward the
Middle East respiratory syndrome coronavirus (MERS-CoV) viral entry (Kim et al. 2018). There are other antiviral plant compounds that can affect spike protein. Emodin, for instance, can inhibit the binding of the protein to its receptor ACE2 and block viral penetration into cells (Ho et al. 2007; Schwarz et al. 2011). In this present study, sissostrin (ZO-40), luteolin (ZO-41), curcumin PE (ZO-43), isoquercitrin (SO-31), Kaempferol 3-O-rutinoside (SO-36), neodiosmin (SO-37), quercetin (AD-13), quercetagetin (AD-14), chicoric acid (AD-17), and querciturone (AD-18) with binding energies of $-8.643 /-9.178,-8.081 /-5.89,-7.013 /-8.216,-9.517 /-9.43$, $-10.575 /-8.943,-10.208 /-9.144,-7.279 /-5.975,-8.396 /$ $-6.994,-9.457 /-9018$, and $-9.256 /-9.904 \mathrm{kcal} / \mathrm{mol}$ exhibited high binding affinity with both or one of studied targets for spike protein (6VW1/6VSB) and are introduced as potential viral entry inhibitors. In an in-silico study by Pandey et al. (2020), SARS-CoV-2 spike protein with PDB-ID: 6VYB was targeted by some flavonoids and non-flavonoids compounds and similar to our results luteolin, curcumin, and quercetin could bind to S2 Domain and C-terminal of S1 domain with energies of $-8.2,-7.1$, and $-8.5 \mathrm{kcal} / \mathrm{mol}$ respectively. The binding energies for Kaempferol 3-O-rutinoside (SO-36) in our study were higher than the value for Kaempferol reported in Pandey et al. (2020) study (-10.575/-8.943 versus -7.4 $\mathrm{kcal} / \mathrm{mol}$ ). Kiran et al. (2020) also showed high LFrank scores for luteolin from Kabasura Kudineer and quercetin from JACOM (a novel herbal formulation) and 6VSB using Cresset Flare software. Our results from iso-quercitrin (SO-31) and 6VSB with a binding energy of $-9.43 \mathrm{kcal} / \mathrm{mol}$ were comparable with the result of Hiremath et al. (2021) from Phyllanthus amarus (-8.60 kcal/mol with quercitrin).

In an experimental study by Yi et al. (2004) it is shown that luteolin and quercetin have inhibitory activity against SARS-CoV through interference on the fusion process and 
Table 4 RMSD value of docked ligands in comparison with the standard ligand of nelfinavir

\begin{tabular}{|c|c|c|c|c|c|c|c|c|c|}
\hline \multirow[t]{2}{*}{ Ligand } & \multicolumn{4}{|l|}{ RMSD } & \multirow[t]{2}{*}{ Ligand } & \multicolumn{4}{|l|}{ RMSD } \\
\hline & 6VW1 & 6VSB & 6LU7 & $6 \mathrm{M} 03$ & & 6VW1 & 6VSB & 6LU7 & $6 \mathrm{M} 03$ \\
\hline Lopinavir & 5.833 & 5.751 & 5.807 & 6.431 & $\mathrm{AD}-15$ & 5.266 & 5.02 & 6.054 & 5.003 \\
\hline Nelfinavir & 0 & 0 & 0 & 0 & AD-16 & 5.318 & 5.6 & 5.628 & 5.074 \\
\hline Sa-O-1 & 4.037 & 4.233 & 4.078 & 4.054 & AD-17 & 6.195 & 5.616 & 7.023 & 5.197 \\
\hline Sa-O-2 & 4.345 & 4.243 & 3.961 & 3.502 & AD-18 & 4.915 & 5.247 & 6.43 & 4.886 \\
\hline $\mathrm{Sa}-\mathrm{O}-3$ & 3.55 & 3.477 & 4.371 & 3.523 & AD-19 & 5.767 & 5.623 & 5.737 & 5.945 \\
\hline Sa-O-4 & 4.34 & 4.162 & 4.618 & 3.956 & $\mathrm{AD}-20$ & 4.917 & 5.178 & 5.804 & 4.758 \\
\hline $\mathrm{Sa}-\mathrm{O}-5$ & 3.979 & 3.908 & 4.073 & 3.604 & ZO-1 & 4.593 & 4.242 & 3.972 & 4.01 \\
\hline Sa-O-6 & 4.134 & 4.391 & 3.908 & 3.968 & $\mathrm{ZO}-2$ & 4.703 & 4.699 & 3.863 & 4.006 \\
\hline Sa-O-7 & 3.86 & 3.715 & 4.085 & 3.562 & ZO-3 & 5.117 & 4.885 & 4.907 & 3.944 \\
\hline Sa-O-8 & 4.594 & 4.802 & 4.456 & 3.777 & ZO-4 & 4.865 & 5.032 & 4.619 & 4.252 \\
\hline Sa-O-9 & 4.478 & 4.683 & 4.215 & 4.102 & ZO-5 & 4.531 & 5.304 & 4.802 & 4.991 \\
\hline Sa-O-10 & 4.705 & 5.107 & 5.001 & 4.045 & ZO-6 & 5.682 & 6.002 & 6.014 & 5.37 \\
\hline Sa-O-11 & 4.656 & 4.777 & 4.485 & 3.95 & ZO-7 & 6.229 & 5.983 & 5.944 & 5.6 \\
\hline Sa-O-12 & 4.558 & 4.41 & 4.493 & 3.895 & ZO-8 & 5.926 & 5.247 & 5.771 & 3.985 \\
\hline Sa-O-13 & 4.943 & 5.207 & 4.421 & 5.228 & ZO-9 & 5.927 & 5.804 & 6.207 & 5.373 \\
\hline $\mathrm{Sa}-\mathrm{O}-14$ & 4.737 & 5.065 & 5.387 & 4.745 & ZO-10 & 6.64 & 6.077 & 6.652 & 6.338 \\
\hline Sa-O-15 & 5.254 & 5.626 & 5.388 & 5.107 & ZO-11 & 5.354 & 4.983 & 5.792 & 5.116 \\
\hline Sa-O-16 & 5.531 & 5.873 & 5.527 & 5.552 & ZO-12 & 5.354 & 5.064 & 6.445 & 5.147 \\
\hline Sa-O-17 & 5.51 & 5.68 & 5.307 & 4.46 & ZO-13 & 5.772 & 5.917 & 5.823 & 5.92 \\
\hline Sa-O-18 & 6.091 & 5.66 & 6.125 & 5.358 & ZO-14 & 4.8 & 4.906 & 4.575 & 4.223 \\
\hline Sa-O-19 & 5.155 & 5.443 & 5.889 & 4.809 & ZO-15 & 5.096 & 5.152 & 4.564 & 4.93 \\
\hline Sa-O-20 & 5.21 & 5.232 & 5.786 & 4.674 & ZO-16 & 5.185 & 5.229 & 5.013 & 4.02 \\
\hline Sa-O-21 & 5.632 & 5.891 & 5.754 & 5.493 & ZO-17 & 4.442 & 4.633 & 4.117 & 3.889 \\
\hline Sa-O-22 & 5.439 & 5.482 & 6.512 & 5.651 & ZO-18 & 5.654 & 5.622 & 6.473 & 4.891 \\
\hline Sa-O-23 & 5.063 & 5.681 & 5.967 & 5.633 & ZO-19 & 5.654 & 5.622 & 6.473 & 4.891 \\
\hline $\mathrm{Sa}-\mathrm{O}-24$ & 6.204 & 6.7 & 6.301 & 6.189 & ZO-20 & 5.389 & 5.592 & 5.855 & 5.132 \\
\hline Sa-O-25 & 5.911 & 6.22 & 5.932 & 5.786 & ZO-21 & 5.803 & 5.392 & 6.147 & 5.584 \\
\hline Sa-O-26 & 6.258 & 5.757 & 6.861 & 6.177 & ZO-22 & 4.446 & 4.827 & 5.103 & 4.636 \\
\hline Sa-O-27 & 5.846 & 6.024 & 5.737 & 5.901 & ZO-23 & 5.035 & 5.799 & 5.895 & 5.608 \\
\hline Sa-O-28 & 5.374 & 5.87 & 5.935 & 5.26 & ZO-24 & 4.908 & 4.623 & 6.265 & 5.849 \\
\hline Sa-O-29 & 5.632 & 5.777 & 6.246 & 5.714 & ZO-25 & 5.509 & 5.296 & 6.104 & 5.675 \\
\hline $\mathrm{Sa}-\mathrm{O}-30$ & 5.688 & 5.419 & 6.433 & 5.101 & ZO-26 & 4.726 & 4.726 & 3.687 & 3.903 \\
\hline Sa-O-31 & 5.658 & 5.529 & 6.161 & 5.415 & ZO-27 & 4.777 & 5.05 & 3.963 & 3.864 \\
\hline $\mathrm{Sa}-\mathrm{O}-32$ & 5.81 & 5.311 & 5.829 & 5.461 & ZO-28 & 4.797 & 5.098 & 4.881 & 4.466 \\
\hline $\mathrm{Sa}-\mathrm{O}-33$ & 6.422 & 5.831 & 6.598 & 5.33 & ZO-29 & 4.727 & 5.16 & 4.51 & 4.327 \\
\hline Sa-O-34 & 6.64 & 6.511 & 6.682 & 5.99 & ZO-30 & 6.202 & 6.05 & 5.784 & 5.174 \\
\hline Sa-O-35 & 6.068 & 5.915 & 6.316 & 5.938 & ZO-31 & 4.814 & 5.2 & 5.772 & 5.502 \\
\hline Sa-O-36 & 5.746 & 5.293 & 5.947 & 5.271 & ZO-32 & 4.854 & 4.49 & 5.633 & 4.482 \\
\hline Sa-O-37 & 6.112 & 5.644 & 7.121 & 5.904 & ZO-33 & 5.224 & 5.366 & 5.273 & 5.362 \\
\hline AD-1 & 3.282 & 3.579 & 4.146 & 3.521 & ZO-34 & 5.242 & 6.021 & 6.849 & 5.876 \\
\hline AD-2 & 4.057 & 4.073 & 3.867 & 3.808 & ZO-35 & 3.789 & 4.06 & 4.191 & 3.764 \\
\hline AD-3 & 3.55 & 3.477 & 4.371 & 3.523 & ZO-36 & 3.423 & 3.486 & 4.381 & 3.501 \\
\hline AD-4 & 4.251 & 4.699 & 4.621 & 4.216 & ZO-37 & 4.782 & 5.133 & 4.559 & 3.71 \\
\hline AD-5 & 3.954 & 4.04 & 3.498 & 3.553 & ZO-38 & 4.733 & 5.207 & 4.949 & 4.068 \\
\hline AD-6 & 4.401 & 4.251 & 3.66 & 4.434 & ZO-39 & 4.305 & 4.308 & 4.466 & 3.918 \\
\hline AD-7 & 3.979 & 3.958 & 3.841 & 4.071 & ZO-40 & 5.429 & 5.661 & 5.593 & 4.916 \\
\hline AD-8 & 4.391 & 4.53 & 3.577 & 3.844 & ZO-41 & 6.329 & 6.512 & 7.541 & 6.061 \\
\hline
\end{tabular}


Table 4 (continued)

\begin{tabular}{|c|c|c|c|c|c|c|c|c|c|}
\hline \multirow[t]{2}{*}{ Ligand } & \multicolumn{4}{|l|}{ RMSD } & \multirow[t]{2}{*}{ Ligand } & \multicolumn{4}{|l|}{ RMSD } \\
\hline & 6VW1 & $6 \mathrm{VSB}$ & 6LU7 & $6 \mathrm{M} 03$ & & 6VW1 & 6VSB & 6LU7 & $6 \mathrm{M} 03$ \\
\hline AD-9 & 4.882 & 5.221 & 4.518 & 3.786 & ZO-42 & 4.656 & 4.777 & 4.485 & 3.95 \\
\hline AD-10 & 5.401 & 5.684 & 5.082 & 5.033 & ZO-43 & 5.566 & 5.786 & 5.636 & 5.066 \\
\hline AD-11 & 4.827 & 5 & 5.523 & 4.172 & ZO-44 & 5.855 & 5.93 & 6.769 & 6.404 \\
\hline AD-12 & 5.241 & 5.403 & 4.876 & 5.135 & ZO-45 & 5.273 & 5.078 & 6.636 & 5.567 \\
\hline AD-13 & 4.728 & 5.191 & 4.378 & 4.669 & ZO-46 & 4.59 & 5.261 & 4.217 & 3.649 \\
\hline AD-14 & 5.083 & 5.352 & 5.874 & 4.26 & ZO-47 & 5.872 & 5.262 & 5.695 & 4.631 \\
\hline
\end{tabular}

entry into host cells. Luteolin also is shown to have a high affinity to the S2 subunit of the spike protein in SARS-CoV (IC50: $10.6 \mu \mathrm{M}$ ) and it is postulating that this component can interfere with the viral cell fusion process (Wu et al. 2004).

Docking analysis results for COVID-19 $\mathrm{M}^{\text {pro }}$ structure (6LU7 and 6M03) showed more than 15 components have high binding affinity to the target structures including $3-[(2$ S,3R,4 S,5 S,6R) 4,5-dihydroxy-6-(hydroxymethyl) 3-[(2 S,3R,4 S,5R)_3,4,5-rihydroxyoxan-2-yl]oxyoxan-2-yl] oxy-2-(3,4-dihydroxypheny 1)_5-hydroxy-7methoxychromen-4-one (ZO-13), [5-acetyloxy-1,7-bis (3,4-dihydroxyphenyl)heptan-3-yl] acetate (ZO-25), (2E)
5-(3-Acetoxy-6-hydroxy-5,5,8a-trimethyl-2- methylene-4 oxodeca hydro-1- naphthalenyl) 3-methyl-2-pentene-1,4diyl diacetate (ZO-31), sissostrin (ZO-40), and curcumin PE (ZO-43) from $Z$. officinale; SO-18, SO-19, SO-27, SO-29, SO-31, SO-35, SO-36, and SO-37 from S. officinalis, and AD-14 to AD-20 from A. dracunculus (Table 3).

A motif between domains I and II (between amino acids 8-183) of $\mathrm{M}^{\text {pro }}$ contains the substrate-binding site of the enzyme and residues 200 to 300 participate in the proteolytic activity of $\mathrm{M}^{\text {pro }}$ (Anand et al. 2003). In this study, it is shown that mentioned components with high docking scores have formed $\mathrm{H}$-bonds and pi-pi interactions with the amino acids
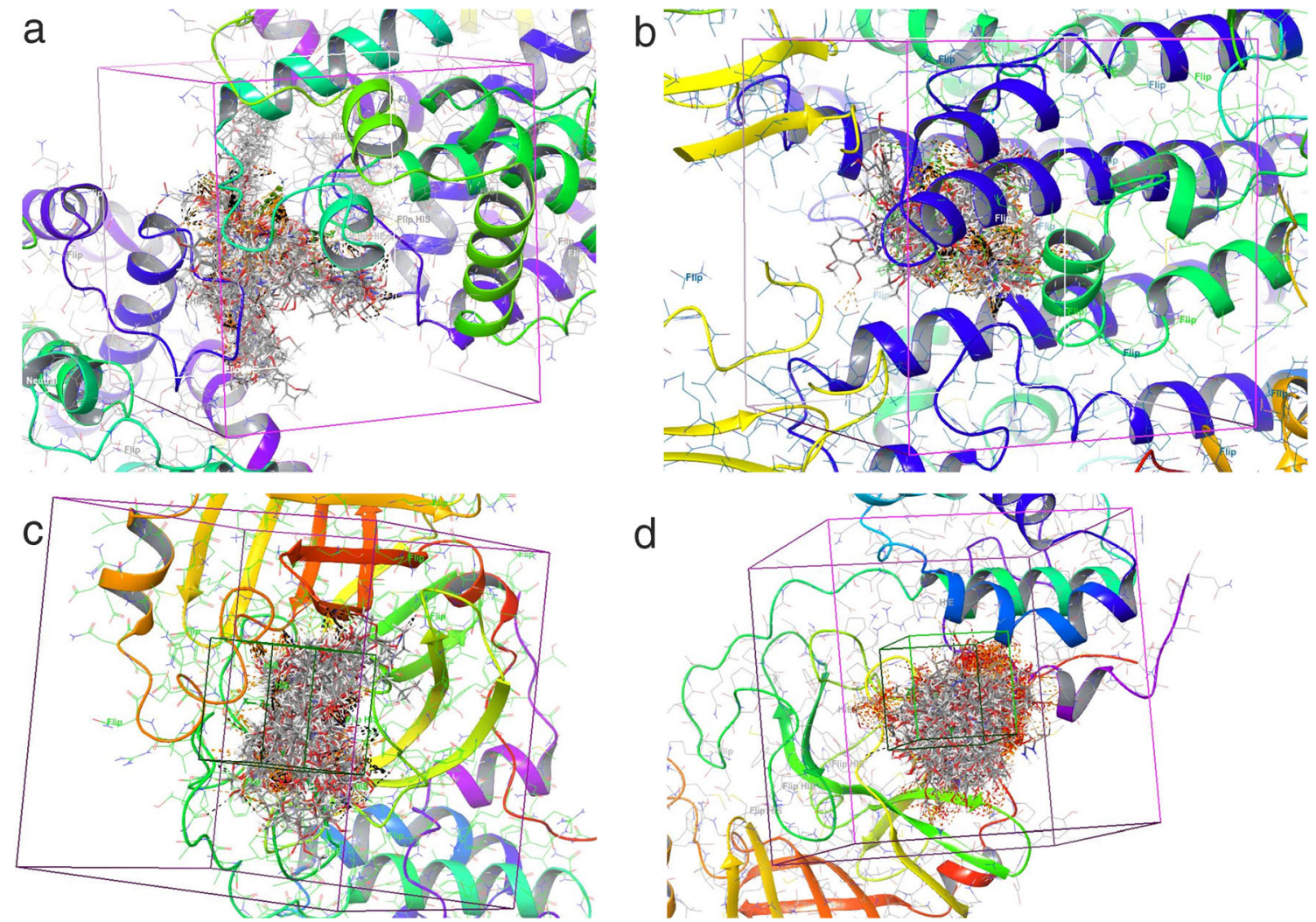

Fig. 4 The superimposed form of all docked ligands against evaluated targets (a) 6VW1; (b) 6VSB; (c) 6LU7; (d) 6M03 
Table 5 Major interactions (H-Bond, Pi-Pi interaction, Ion-Bond) of active ligands against evaluated targets

\begin{tabular}{|c|c|c|c|}
\hline \multirow{3}{*}{$\begin{array}{l}\text { Compd } \\
\text { code }\end{array}$} & \multicolumn{3}{|c|}{ Major interactions (H-Bond, Pi-Pi interaction, Ion-Bond) } \\
\hline & \multicolumn{2}{|l|}{$\mathrm{M}^{\text {pro }}$} & \multirow{2}{*}{$\frac{\mathrm{COV}-2-\mathrm{SP}}{6 \mathrm{VSB}}$} \\
\hline & $6 \mathrm{MO} 3$ & 6LU7 & \\
\hline ZO-13 & $\begin{array}{l}\text { HIS-41, SER-46, } \\
\text { GLU-166 }\end{array}$ & $\begin{array}{l}\text { ARG-105 (2 Int.), } \\
\text { GLN-110, ASP-153 (2 } \\
\text { Int.) }\end{array}$ & $\begin{array}{l}\text { GLY-B: 381, GLY-C: 381, THR-A: 385, LYS-C: } 386 \text { (2 } \\
\text { Int.), ASN-A: 388, ASP-B: 389, ASN-B: 542, GLY-C: } \\
\text { 545 (2 Int.), GLY-B: 547, THR-B: 547, THR-C: 547, } \\
\text { PRO-A: 527, LYS-A: 529, TYR-A:756, ASP-A:994, } \\
\text { ARG-A: } 995 \text { ARG-B:995 (2 Int.), THR-A: } 998\end{array}$ \\
\hline ZO-25 & $\ldots$ & $\begin{array}{l}\text { THR-111, GLN-110, } \\
\text { ILE-249 }\end{array}$ & $\begin{array}{l}\text { GLY-C: } 381 \text {, CYS-C: } 391 \text {, ALA-B: } 520 \text { (2 Int.), PHE-C: } \\
\text { 543, PHE-C: 565, THR-B: 998, THR-C: } 998\end{array}$ \\
\hline ZO-31 & $\begin{array}{l}\text { HIS-41, PHE-140, } \\
\text { GLU-166 (2 Int.) }\end{array}$ & $\begin{array}{l}\text { GLN-110, THR-111, } \\
\text { ILE-249 (2 Int.) }\end{array}$ & $\begin{array}{l}\text { ASP-A: 364, SER-A: } 366 \text { (2 Int.), GLN-A: 580, THR-B: } \\
\text { 998, THR-C: } 998\end{array}$ \\
\hline $\mathrm{ZO}-40$ & $\begin{array}{l}\text { SER-46 (2 Int.), } \\
\text { HIE-164, GLU-166, } \\
\text { GLN-189 }\end{array}$ & $\begin{array}{l}\text { LYS-102, GLN-110 (2 } \\
\text { Int.), THR-111, } \\
\text { ASN-151, ILE-152, } \\
\text { ASP-153 }\end{array}$ & $\begin{array}{l}\text { GLU-B: } 96 \text { (2 Int.), ILE-B: 101, ASN-B: 121, ARG-B: } 190 \\
\text { (2 Int.), GLY-B: 381, THR-A: 385, SER-B: 388, } \\
\text { ASP-A: 389, LEU-C: 518, PRO-A: 527, LYS-A: 528, } \\
\text { ASN-C: } 544 \text { (2 Int.), GLY-B: 545, GLY-C: 545, } \\
\text { ARG-C: 567, trople, SER-C: 730, TYR-A: 756, THR-C: } \\
\text { 866, ASP-C: } 867 \text { (2 Int.), ASP-A: } 994 \text { (2 Int.), ASP-B: } \\
\text { 994, THR-B: 998, THR-C: 998, PRP-C: } 1057\end{array}$ \\
\hline
\end{tabular}

ZO-41 994, THR-B: 998, THR-C: 998, PRP-C: 1057

6VW1

SER-371, PHE-377,

LYS-378, CYS-379

SER-371 (2 Int.), ARG-408, ILE-410

TYR-369, SER-371, THR-376, PHE-377

ZO-43 HIS-41, LEU-141, ASN-142, GLU-166, GLN-189

ZO-45

SO-18 THR-26, SER-46, GLY-143, GLU-166 (2 Int.), GLN-189

ARG-015 (2 Int.), THR-111 (2 Int.), ASP-153

GLN-110 (2 Int.), THR-111, ASP-153, ASP-295

SO-20

SO-22

SO-25

SO-27 THR-25, THR-26 (2 Int.), GLU-166

SO-28

SO-29 HIS-41, GLU-166 (2 Int.)

SO-30

ARG-A: 328, PRO-A: 527, LYS-A: 529, ASN-A: 542, SER-B: 98, ASN-B:121 (2 Int.), ARG-B: 190 triple, SER-A: 730, LEU-A: 861, ASP-A: 867, PHE-B: 970, ASP-A:994, ASP-B: 994, THR-C: 998

ASP-B: 389, ASP-A: 364 (2 Int.), PRO-A: 527 (2 Int.), LYS-A: 529, ASN-B: 542 (2 Int.), MET-A: 731,

LYS-A: 733, ARG-A: 815, PHE-A: 823, LEU-A: 861, ASP-A: 867, HIS-A: 1058, TYR C: 756, PHE A:970, GLN B:1002

SER-A: 325, ARG-A: 328, PRO-A: 527, ASP-C: 428, PHE-C: 464, PHE-C: 515, LEU-C: 517, LEU-C: 518, LYS-A: 528, LYS-A: 529, LYS-C: 733, PHE-C: 823, LEU-C: 861, ASP-C: 867, ASP-A: 994, ASP-C: 994 (2 Int.), ARG-B: 995, THR-B: 998

GLY-B: 381, GLY-C: 381, SER-B: 383 (2 Int.), Cys-C: 391, PRO-A: 527 (2 Int.), LYS-A: 529, GLY-C: 545, SER-A: 730, LYS-A: 733, LEU-A: 861, ASP-A: 867, PRO-A: 1057 ,

ASP-C: 389 (2 Int.), THR-A: 523 (2 Int.), CYS-A: 525, LYS-A: 528 (2 Int.), LYS-A: 528, ASN-C: 542, GLY-C: 545, THR-C: 547 (2 Int.), TYR-C: 756, ASP-A: 994, ASP-C: 994, THR-C: 998, ARG-A: 995

CYS-B: 391, LEU-B: 518, ALA-B: 520, THR-B: 547, ASP-B: 571, TYR-C: 756, PHE-C: 970, ASP-A: 994, ASP-C: 994, THR-A: 998, THR-B: 998

CYS-C: 391, ALA-C: 520, ARG-B: 995, PHE-A: 970 (2 Int.), THR-B: 998, GLN-B:1002

ASP-A: 364 (2 Int.), PRO-A: 527, LYS-A: 529 (2 Int.), PHE-A: 970 (2 Int.), ARG-B: 995, THR-B: 998

PHE-A: 970, PHE C: 970, ASP-A: 994, ASP-B: 994, ARG-C: 995, THR-B: 998, GLN-A: 1002

GLY-C: 381, LEU-C: 518, ALA-C: 520 (2 Int.), ASN-C: 544, ASN-B: 542, MET-A: 731, LYA-A: 733, ARG-A: 815 (2 Int.), VAL-A: 826, LEU-A: 861, ASP-A: 867, ASP-A: 994, ARG-A: 995, THR-C: 998, HIS-A: 1058 PHE-A: 970, PHE C: 970, ASP-A: 994, ASP-B: 994, ARG-A: 995, ARG-C: 995, THR-B: 998, GLN-A: 1002
TYR-369, SER-371, PHE-374, THR-376, LYS-378

SER-371, PHE-377, LYS-378, LYS-378, CYS-379

SER-375, PHE-377, LYS-378, CYS-379

TYR-369, THR-376, LYS-378, LYS-378, ALA-384

SER-371 (2 Int.), LYS-378, CYS-379, ALA-384 
Table 5 (continued)

Compd Major interactions (H-Bond, Pi-Pi interaction, Ion-Bond)

code
$\mathrm{M}^{\text {pro }}$
COV-2-SP

$6 \mathrm{MO} 3$

6LU7

6VSB

6VW1

$\begin{array}{ccc} & & \\ \text { SO-31 } & \text { THR-25, GLU-166 (2 } \\ & \text { Int.), GLY-143 } & \\ & & \\ \text { SO-32 } & & \text { GLN-110 triple, ASP-153 } \\ & & \text { PHE-294 } \\ \text { SO-35 } & \text { HIS-41, ASN-119, } & \text { GLN-110, THR-111, } \\ & \text { LEU-141, GLY-143, } & \text { SER-158, ILE-249 } \\ & \text { GLU-166, GLN-189 } & \\ & & \\ \text { SO-36 } & \text { SER-46, LEU-141, } & \text { LYS-102, ARG-015, } \\ & \text { ASN-142, GLY-143, } & \text { THR-111, ASP-153 } \\ & \text { GLU-166 } & \text { quadruple }\end{array}$

SO-37 HIS-41, GLU-166 (2

Int.), GLN-189

AD-13

AD-14 THR-25, SER-46, GLY-143, GLU-166 (2 Int.)

AD-15

AD-16 THR-26, ASN-142, GLY-143, HIE-164, GLU-166, GLN-189

GLN-110 (2 Int.), THR-111, ASP-153 (2 Int.)

AD-17 HIS-41, GLU-166 (2

GLN-110, THR-111, ASP-153, ILE-249 (2 Int.)
AD-18 PHE-140, ASN-142, GLN-110 (2 Int.), GLY-143, GLU-166 THR-111, ASP-153 (2 Int.)

SER-A: 366, CYS-B: 379 (2 Int.), LYS-B: 386, THR-A: 385, ASN-A: 388, GLY-B: 381, LYS-B: 386, ASP-A: 389 (2 Int.), ASP-B: 389, ASN-B: 542, GLY-B: 545 (2 Int.), PRO-A: 527 (2 Int.), PHE-A: 970, PHE-C: 970, ASP-A: 994, ASP-B: 994, THR-998 B, ARGC: 995

ILE-B: 101, PRO-B: 174, PHE-B: 175, SER-B: 205 , ASP-C: 389 (2 Int.), ASP-A: 364, THR-A: 385, ASN-A: 388, ASP-A: 389, PRO-A: 527, ASN-C: 542, GLY-C: 545, THR-C: 547, PHE-A: 970, ASP-A: 994 (2 Int.), ASP-B: 994, ASP-C: 994

SER-B: 98, ILE-B: 101, ASN-B: 121, ARG-B: 190, SER-A: 325, GLY-B: 381, GLY-C: 381, SER-B: 388, ASP-B: 389, PRO-A: 527 (2 Int.), LYS-A: 528, GLY-C: 545, ARG-C: 567 (2 Int.), ASP-C: 571, SER-A: 730, SER-C: 730, ARG-C: 815, LEU-C: 828, LEU-A: 861, THR-C: 866, ASP-A: 867 (2 Int.), ASP-C: 867 (2 Int.), ASP-A: 994, ARG-A: 995, ARG-A:995, ARG-B: 995, ARG-B: 995, THR-C: 998

CYS-A: 361 (2 Int.), CYS-C: 391, ASN-A: 544 (2 Int.), ASP-C: 571 (2 Int.), LYS-C: 733, ARG-C: 815 (2 Int.), LEU-C: 861, THR-C: 866, ASP-C: 867, ASP-C: 994, ARG-A: 995, ARG-B: 995

GLU-B: 96, ILE-B: 101, ARG-B: 190, GLY-B: 381 (2 Int.), GLY-C: 381 (2 Int.), LYS-B: 386 (2 Int.), CYS-C: 391, ASN-B: 542, GLY-C: 545

ASP-A: 389, ALA-C: 520 (2 Int.), ASN-B: 544, PRO-A: 527 (2 Int.), LYS-A: 528, LYS-A: 529, GLY-C: 545 (2 Int.), THR-B: 547 (2 Int.), ASN-A: 547, CYS-C: 591, LYS-C: 733 (2 Int.), LEU-C: 861, ASP-C: 867 (2 Int.), THR-C: 866, PHE-C: 970, THRC: 998

GLU-B: 96, ILE-B: 101, ARG-B: 102, ASN-B: 121, ARG-B: 190, CYS-B: 379 (2 Int.), GLY-B: 381 (2 Int.), SER-B: 383, SER-C: 383, THR-A: 385, LYS-B: 386, ASN-A: 388, PHE-B: 429, PRO-A: 527, GLY-C: 545 (2 Int.), PHE-C: 565, LYS-A: 733, LEU-A: 861. ASP-A: 867 (2 Int.), PHE-A: 970, ASP-A: 994, ASP-B: 994, ARG-C: 995, THR-B: 998

GLY-B: 381, SER-B: 388, PRO-A: 527, LYS-A: 528, LYS-A: 529, ASN-A: 542, (2 Int.), ASN-B: 542, GLY-B: 545, MET-A: 731, ASP-A: 775, ARG-A: 815, PHE-A: 823, ASP-A: 867, ASP-A:994, THR-A:998, THR-B: 998, THR-C:998

GLU-B: 96, SER-B: 98, ASN-B: 121, ARG-B: 190 triple, SER-371 (2 Int.), ARG-B: 190, GLY-B: 381, THR-A: 385, ASN-A: 388, ASP-A: 389, ASP-B: 389, ASN-B: 542, THR-B: 547, SER-A: 730, MET-A: 731, PHE-C:970, ASP-A: 867, ASP-994-A:994, ASP-B:994, THR-B: 998, ARG-995, HIS-A: 1058, HIS-A: 1058
SER-375, THR-376, PHE-377, PHE-377, ALA-384

THR-376 (2 Int.), PHE-377, CYS-379

THR-376, PHE-377, LYS-378, LYS-378, ARG-408, ILE-410

TYR-369, SER-371, THR-376, PHE-377, CYS-379

SER-371, PHE-374, SER-375, ARG-408, ILE-410

VAL-407, ARG-408

SER-371, PHE-374, LYS-378

SER-371 (2 Int.), PHE-377, LYS-378

THR-369, SER-371, PHE-377, LYS-378, CYS-379

TYR-369, SER-371, LYS-378, CYS-379

PHE-377, LYS-378 
Table 5 (continued)

\begin{tabular}{|c|c|c|c|c|}
\hline \multirow{3}{*}{$\begin{array}{l}\text { Compd } \\
\text { code }\end{array}$} & \multicolumn{4}{|c|}{ Major interactions (H-Bond, Pi-Pi interaction, Ion-Bond) } \\
\hline & \multicolumn{2}{|l|}{$\mathrm{M}^{\text {pro }}$} & \multicolumn{2}{|l|}{ COV-2-SP } \\
\hline & $6 \mathrm{MO} 3$ & 6LU7 & 6VSB & 6VW1 \\
\hline AD-19 & $\begin{array}{l}\text { THR-26, PHE-140, } \\
\text { ASN-142, GLU-166 } \\
\text { (2 Int.) dd }\end{array}$ & $\begin{array}{l}\text { GLN-110 (2 Int.), } \\
\text { ASN-151, ASP-153 (2 } \\
\text { Int.) }\end{array}$ & $\begin{array}{l}\text { GLU-B: 96, ILE-B: 101, ASN-B: 121, ARG-B: 190, } \\
\text { GLY-C: } 381 \text { (2 Int.), SER-B: } 383 \text { (2 Int.), THR-A: 385, } \\
\text { ASN-A: 388, ASP-A: 389, ASP-B: 389, LYS-A: 529, } \\
\text { ASN-B: 542, GLY-C: } 545 \text { (2 Int.), THR-B: 547, } \\
\text { THR-C: } 547,\end{array}$ & $\begin{array}{l}\text { SER-371, PHE-374 (2 } \\
\text { Int.) }\end{array}$ \\
\hline AD-20 & $\begin{array}{l}\text { THR-26 (2 Int.), } \\
\text { PHE-140, GLU-166, } \\
\text { GLN-189 }\end{array}$ & & $\begin{array}{l}\text { ARG-A: 328, GLY-B: 381, ASN-A: 388, ASP-B: } 389, \\
\text { PRO-A: 527, ASN-B: 542, GLY-B: 545, THR-B: 547, } \\
\text { ASP-A: } 994 \text { (2 Int.), ASP-C: 994, ARG-A: } 995\end{array}$ & $\begin{array}{l}\text { SER-371, LYS-378 (2 } \\
\text { Int.), CYS-379 }\end{array}$ \\
\hline
\end{tabular}

2Int: 2 interactions. $\mathrm{A}, \mathrm{B}$, and $\mathrm{C}$ : $\mathrm{A}, \mathrm{B}$, and $\mathrm{C}$ chains in $6 \mathrm{VSB}$ respectively

105 to 294 of $6 \mathbf{L U} 7$ and H-bonds with residues 25 to 189 of 6M03 (Table 5). Specific interactions are observed in this study between 3-[(2 S,3R,4 S,5 S,6R)_4,5-dihydroxy-6 -(hydroxymethyl)_3-[(2 S, 3R, 4 S, 5R $) \_3,4,5$ trihydroxyoxan-2-yl]oxyoxan-2-yl] oxy-2-(3,4dihydroxyphenyl)_5-hydroxy-7- methoxychromen-4-one (ZO-13), sissostrin (ZO-40), curcumin PE (ZO-43), SO-18, SO-27, SO-29, SO-31, SO-35, SO-36, SO-37, AD-14 to AD-20, and residues of the catalytic binding pocket (GLU-166, HIS-41, GLN-189, LEU-141, GLY-143) of $\mathrm{M}^{\text {pro }}$ (Table 5; Fig. 6).

Supporting similar studies for these observations is from Chen et al. (2006) which showed interactions between quercetin-3- $\beta$-galactoside and His41, GLY-143, SER-144, LEU-141, CYS-145, GLU-166, and GLN-189 residues of SARS-CoV $3 \mathrm{CL}^{\text {Pro }}$. In the mentioned study inhibitory effect of quercetin-3- $\beta$-galactoside is strongly attributed to the H-bonds of the ligand with GLN-189. Another similar work is from Nguyen et al. (2012) on seven flavonoid compounds including quercetin, and an in-silico study by Ryu et al. (2010) which displayed the SARS-CoV $3 \mathrm{CL}^{\text {pro }}$ inhibitory effect of quercetin. In this present study kaempferol 3-O-rutinoside (SO-36) through hydrogen bonds with GLY-143, GLN-189, GLU-166, and LEU-141 confers a good binding score for SO-36 (Fig. 6). This is following the results of a study by Jo et al. (2020) in which the hydrogen bond with Glu166 in the active site of SARS-CoV 3CL ${ }^{\text {pro }}$ and kaempferol was shown.

Binding energies of luteolin (ZO-41) and 6-Methoxy luteolin (SO-15) to $\mathrm{M}^{\text {pro }}$ (6M03) in this study were noticeable. This observation is in line with a recent study by $\mathrm{Yu}$ et al. (2020) which introduces luteolin as a potent compound against COVID-19. The binding affinity between quercetin (AD-13) from A. dracunculus and $\mathrm{M}^{\text {pro }}$ (6M03) in this study was $-6.981 \mathrm{kcal} / \mathrm{mol}$ which was near to the value reported for this compound in Zhang et al. study (2020) $(-6.25 \mathrm{kcal} / \mathrm{mol})$ (Zhang et al. 2020) but higher binding affinities are reported in this study for quercetin derivatives like quercetagetin (AD-14) and querciturone (AD-18) with binding energy values of -8.11 and $-9.53 \mathrm{kcal} / \mathrm{mol}$ respectively. In the mentioned study kaempferol was introduced as a candidate which can inhibit 3 CLpro with a binding affinity of $-6.01 \mathrm{kcal} / \mathrm{mol}$ (Zhang et al. 2020). Higher binding affinity was observed in this study between kaempferol 3-O-rutinoside (SO-36) from S. officinalis and $\mathrm{M}^{\text {pro }}$ (-9.705). Hiremath et al. (2021) have shown binding affinity of some flavonoids from Phyllanthus amarus using AutoDock Vina software and 3CLpro (6LU7) and their results showed accordance with our results from kaempferol (AD-11) and quercetin (AD-13). They have reported -7.70 and $-7.50 \mathrm{Kcal} / \mathrm{mol}$ for mentioned compounds respectively and our obtained figures were -6.88 and -6.98 (Hiremath et al. 2021).

According to the reports from experimental studies, quercetin has shown inhibition activity toward $3 \mathrm{CL}^{\text {pro }}$ with an $\mathrm{IC}_{50}$ value of $73.7 \mu \mathrm{M}$ (Nguyen et al. 2012). Ryu et al. (2010) exhibited the protease inhibitory of luteolin, and quercetin with $\left(\mathrm{IC}_{50}: 20.2\right.$, and $23.8 \mu \mathrm{M}$, respectively). Quercetin has also captured an $\mathrm{IC}_{50}$ of $52.7 \mu \mathrm{M}$ in Park et al. (2017) study. In the latter, $\mathrm{IC}_{50}$ of 5.7 and $116.3 \mu \mathrm{M}$ was reported for curcumin and kaempferol respectively and a prenylated quercetin derivative displayed the most inhibitory activity $\left(\mathrm{IC}_{50}: 3.7\right)$. Curcumin was also reported as a $3 \mathrm{Cl}^{\text {pro }}$ inhibitor in Vero E6 cells (Wen et al. 2007).

In three plants used in this study, 23 components showed high docking scores with both COV-2-SP and $\mathrm{M}^{\text {pro }}$ viral targets (Table 3), among which some flavonoids and phenylpropanoids such as curcumin PE from Z. officinale; kaempferol 3-O-rutinoside, isoquercitrin, and rosmarinic acid from S. officinalis; and chlorogenic acid, chicoric acid, querciturone and isorhamnetin 3-glucuronide from A. dracunculus have shown different therapeutics or antimicrobial properties in medicine or microbiology (Chen and Chen 2013; Hussein et al. 2020; Lee et al. 2013; Lin et al. 
a

6VSB - ZO-13

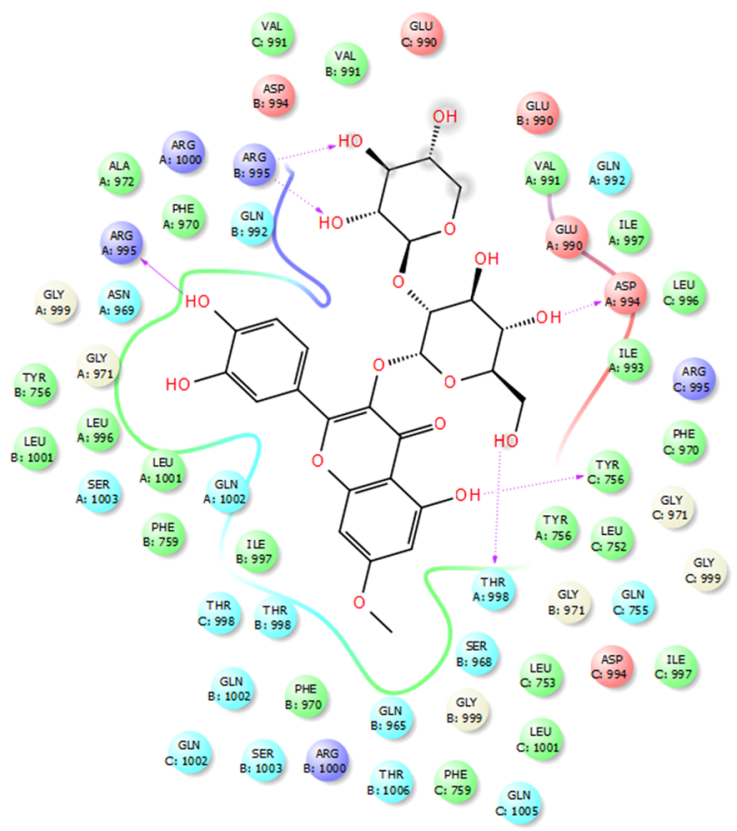

b

6VSB - AD-18

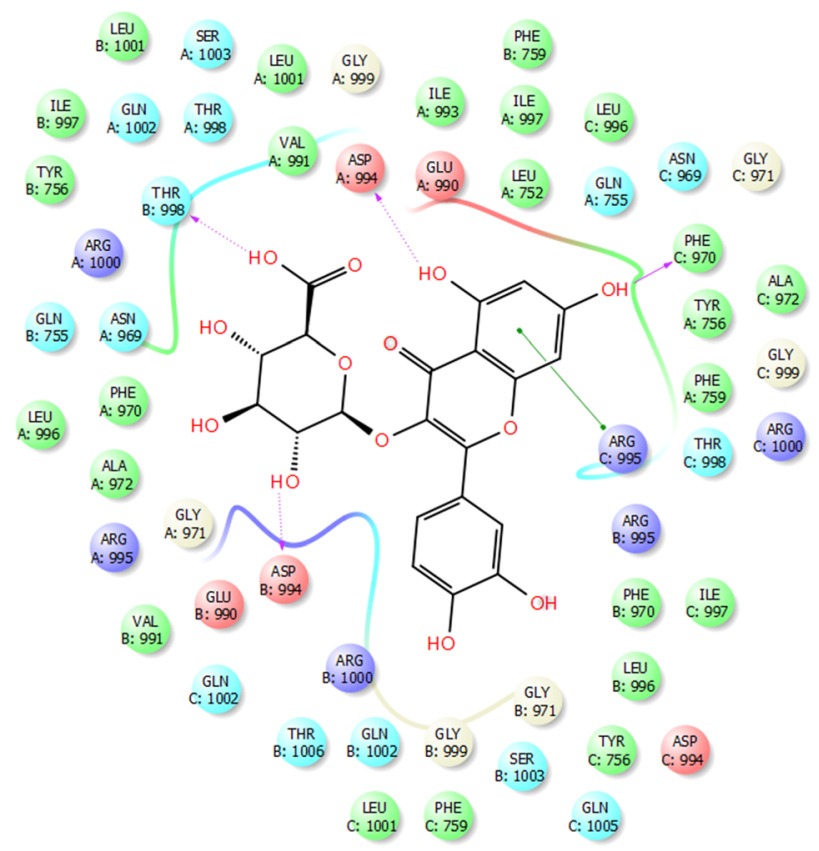

Fig. 5 Docked molecules of 3-[(2 S,3R,4 S,5 S,6R)-4,5-dihydroxy-6 -(hydroxymethyl)-3-[(2 S,3R,4 S,5R)-3,4,5- trihydroxyoxan-2-yl] oxyoxan-2-yl] oxy-2-(3,4- dihydroxyphenyl)-5-hydroxy-7methoxychromen-4-one (ZO-13) (a), Querciturone (AD-18) (b), 2-(3,4-

2019; Nile et al. 2020; Tajik et al. 2017; Wu et al. 2018; Li et al. 2016). So, the different combined usage of the reported compounds with dual interaction with COV-2-SP and $\mathrm{M}^{\text {pro }}$ can be a better strategy for entry and viral replication interruption of the 2019-nCOV.
C

6VSB - SO-27

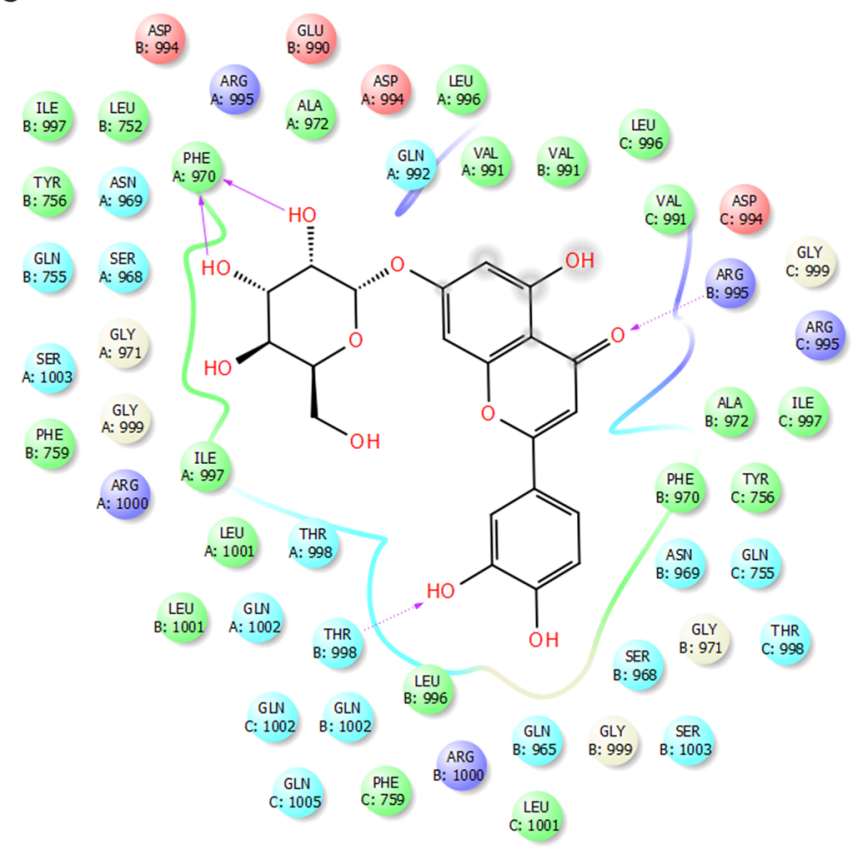

d

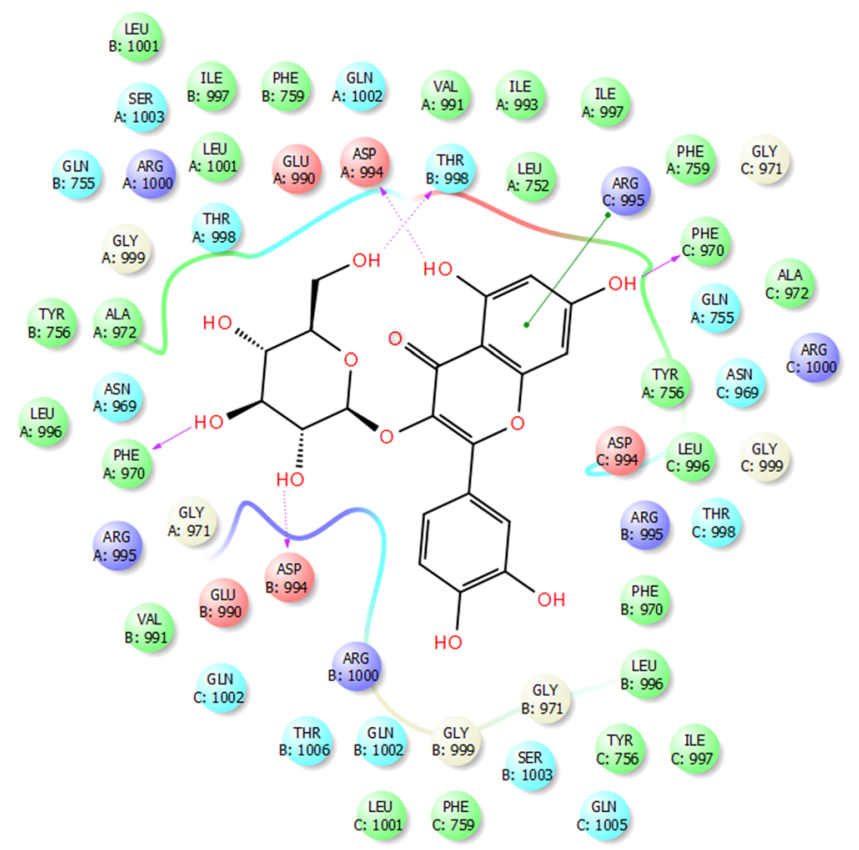

dihydroxyphenyl)-5-hydroxy-7-[3,4,5-trihydroxy-6-(hydroxymethyl) oxan-2-yl] oxychromen-4-one (SO-27) (c), and ISO-quercitrin (SO-31) (d) in the active sites of 6VSB (COV-2-SP). The principal amino acids are evident in the vicinity of the docked molecule

\section{Conclusions}

The molecular networking technique is an accurate tool for the differentiation of the metabolites in plant extracts. Docking analysis results of some compounds in the present study 
a

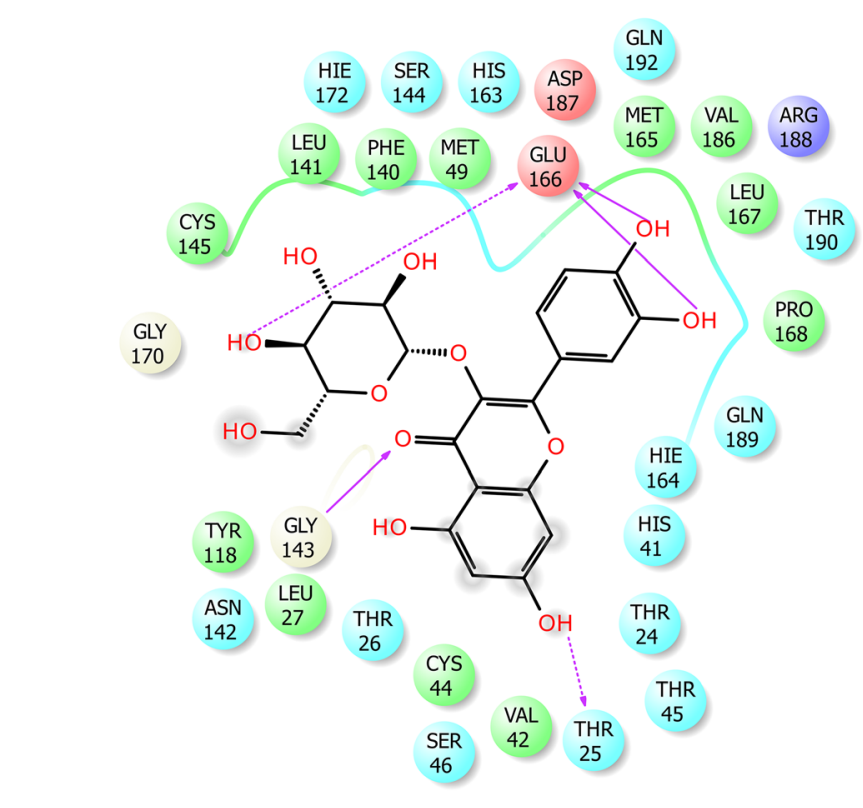

C

\section{M03 - Sa-O-36}

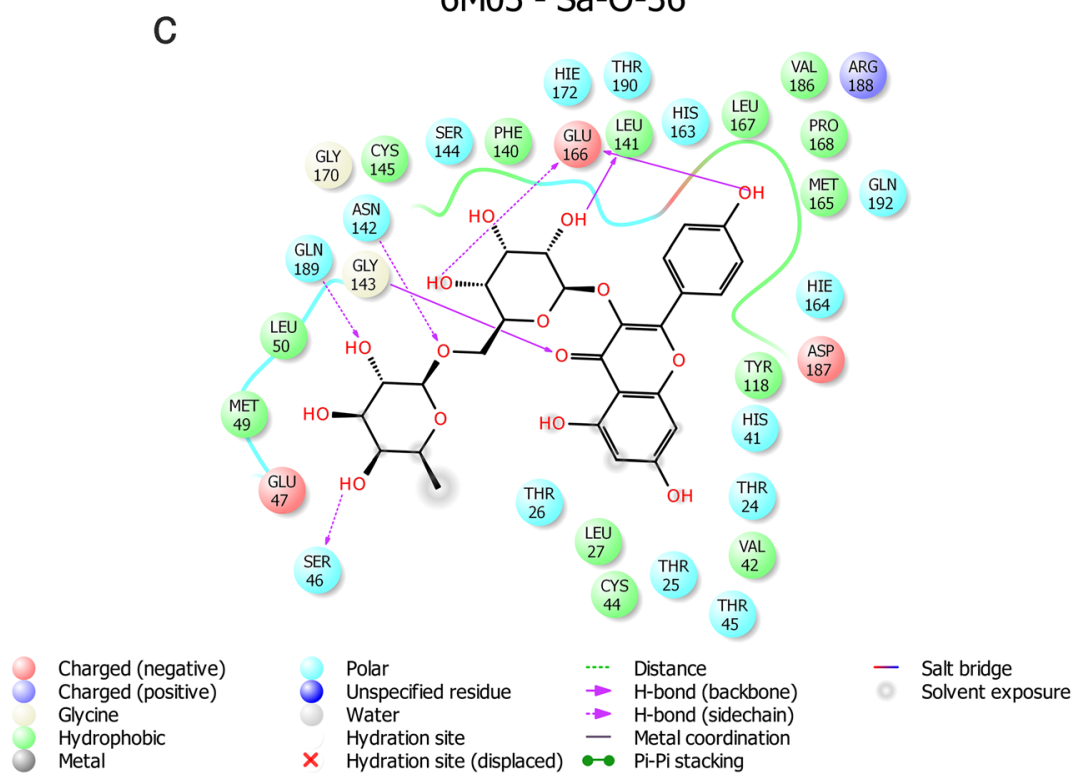

6M03 - Ad-14

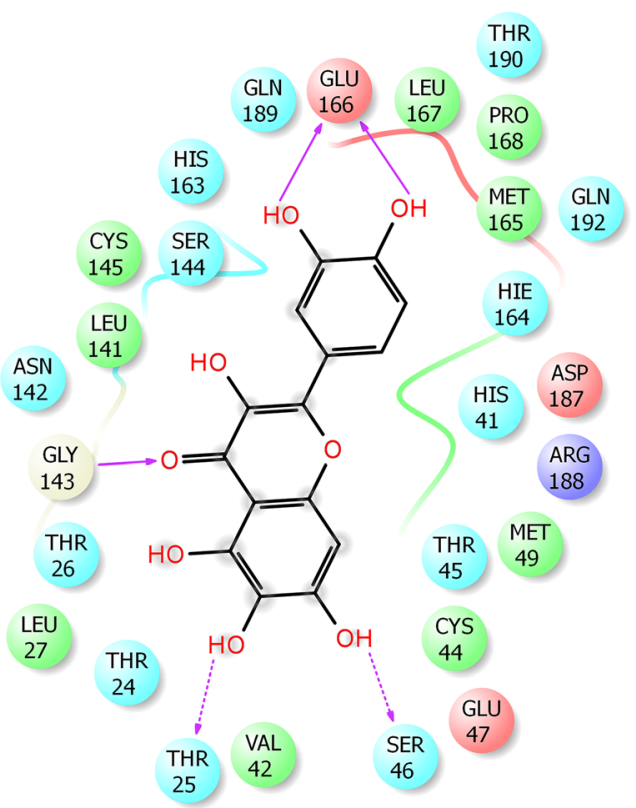

d

\section{M03 - Ad-18}

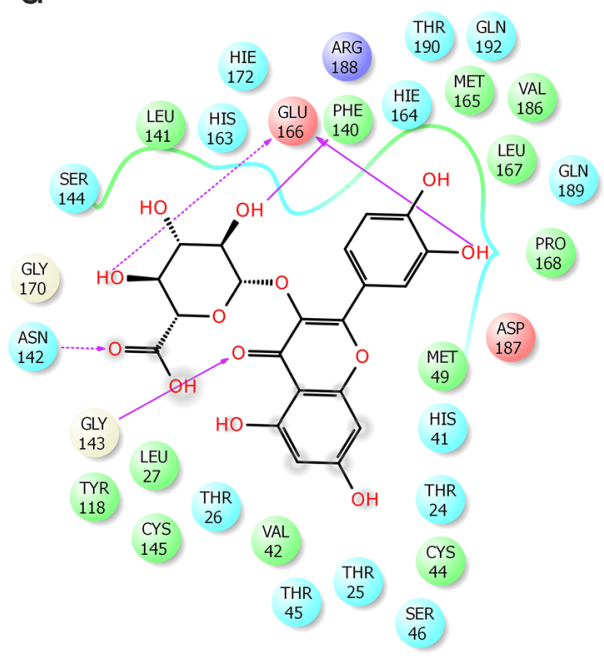

Fig. 6 Docked molecules of ISO-quercitrin (SO-31) (a), Quercetagetin (AD-14) (b), kaempferol 3-O-rutinoside (SO-36) (c), and Querciturone (AD-18) (d) in the active sites of $6 \mathrm{M} 03\left(\mathrm{M}^{\mathrm{pro}}\right)$. The principal amino acids are evident in the vicinity of the docked molecule

showed a high affinity with entry and replication contributing proteins in SARS-CoV-2. Obtained results for some ligands such as luteolin (ZO-41), isoquercitrin (SO-31), quercetin (AD-13), quercetagetin (AD-14), querciturone (AD-18), kaempferol (AD-11), kaempferol 3-O-rutinoside (SO-36), and curcumin (ZO-43) were in accordance with the results of previous experimental/in silico studies. So, these compounds alongside other compounds with high affinity to the virus targets are recommended for further studies in therapeutic aims of 2019-nCOV.
Abbreviations $\mathrm{AD}$, Artemisia dracunculus; ACE-2, Cell surface receptor angiotensin-converting enzyme 2; CoV, Coronavirus; COVID-19, Coronavirus disease 2019; $\mathrm{M}^{\text {pro }}$, Main protease; MN, Molecular Networking; RBD, Receptor-binding domain; SO, Salvia officinalis; SARS-CoV-2, Severe Acute Respiratory Syndrome-related Coronavirus; ZO, Zingiber officinale; 2019-nCOV, 2019 novel Coronavirus; COV-2-SP, 2019-nCOV spike protein; $3 \mathrm{CL}^{\text {pro }}, 3$ C-like-protease

Supplementary Information The online version contains supplementary material available at https://doi.org/10.1007/s11756-021-00881-z. 
Acknowledgements The authors would like to acknowledge Miss Asal Attari for editing this manuscript for the English language.

\section{Declarations}

Conflict of interest The authors have no conflicts of interest to declare that are relevant to the content of this article.

\section{References}

Anand K, Palm GJ, Mesters JR, Siddell SG, Ziebuhr J, Hilgenfeld R (2002) Structure of coronavirus main proteinase reveals combination of a chymotrypsin fold with an extra $\alpha$-helical domain. EMBO J 21:3213-3224. https://doi.org/10.1093/emboj/cdf327

Anand K, Ziebuhr J, Wadhwani P, Mesters JR, Hilgenfeld R (2003) Coronavirus main proteinase (3CLpro) structure: basis for design of anti-SARS drugs. Science 300:1763-1767. https://doi.org/10.1126/ science. 1085658

Babaeekhou L, Ghane M (2020) Antimicrobial activity of ginger on cariogenic bacteria: molecular networking and molecular docking analyses. J Biomol Struct Dyn 39:2164-2175. https://doi.org/10. 1080/07391102.2020.1745283

Bosch BJ, Van der Zee R, De Haan CA, Rottier PJ (2003) The coronavirus spike protein is a class I virus fusion protein: structural and functional characterization of the fusion core complex. J Virol 77: 8801-8811. https://doi.org/10.1128/JVI.77.16.8801-8811.2003

Burkard C, Verheij MH, Wicht O, van Kasteren SI, van Kuppeveld FJ, Haagmans BL, de Haan CA (2014) Coronavirus cell entry occurs through the endo-/lysosomal pathway in a proteolysis-dependent manner. PLoS Pathog 10:e1004502. https://doi.org/10.1371/ journal.ppat.1004502

Chen AY, Chen YC (2013) A review of the dietary flavonoid, kaempferol on human health and cancer chemoprevention. Food Chem 138:2099-2107. https://doi.org/10.1016/j.foodchem.2012. 11.139

Chen L, Li J, Luo C, Liu H, Xu W, Chen G, Shen X (2006) Binding interaction of quercetin-3- $\beta$-galactoside and its synthetic derivatives with SARS-CoV 3CLpro: Structure-activity relationship studies reveal salient pharmacophore features. Bioorg Med Chem 14:82958306. https://doi.org/10.1016/j.bmc.2006.09.014

Dimitrov DS (2004) Virus entry: molecular mechanisms and biomedical applications. Nat Rev Microbiol 2:109-122. https://doi.org/10. 1038/nrmicro817

Du L, He Y, Zhou Y, Liu S, Zheng BJ, Jiang S (2009) The spike protein of SARS-CoV a target for vaccine and therapeutic development. Nat Rev Microbiol 7:226-236. https://doi.org/10.1038/nrmicro2090

Duric K, Kovac Besovic EE, Niksic H, Muratovic S, Sofic E (2015) Anticoagulant activity of some Artemisia dracunculus leaf extracts. Bosn J Basic Med Sci 15:9. https://doi.org/10.17305/bjbms.2015. 384

Goldman JD, Lye DCB, Hui DS, Marks KM, Bruno R, Montejano R, Spinner CD, Galli M, Ahn MY, Nahass RG, Chen YS, SenGupta D, Hyland RH, Osinusi AO, Cao H, Blair C, Wei X, Gaggar A, Brainard DM, Towner WJ, Muñoz J, Mullane KM, Marty FM, Tashima KT, Diaz G, Subramanian A, GS-US-540-5773 Investigators (2020) Remdesivir for 5 or 10 days in patients with severe Covid-19. N Engl J Med 383(19):1827-1837. https://doi.org/ 10.1056/NEJMoa2015301

Hernández Saavedra D, Pérez Ramírez IF, Ramos Gómez M, Mendoza Díaz S, Loarca Pina G, Reynoso Camacho R (2016) Phytochemical characterization and effect of Calendula officinalis, Hypericum perforatum, and Salvia officinalis infusions on obesity-associated cardiovascular risk. Med Chem Res 25:163-172. https://doi.org/ 10.1007/s00044-015-1454-1

Herold J, Raabe T, Schelle-Prinz B, Siddell S (1993) Nucleotide sequence of the human coronavirus 229E RNA polymerase locus. Virology 195:680-691. https://doi.org/10.1006/viro.1993.1419

Hiremath S, Kumar HDV, Nandan M, Mantesh M, Shankarappa KS, Venkataravanappa V, Basha CRJ, Reddy CNL (2021) In silico docking analysis revealed the potential of phytochemicals present in Phyllanthus amarus and Andrographis paniculata, used in Ayurveda medicine in inhibiting SARS-CoV-2. 3 Biotech 11:44. https://doi.org/10.1007/s13205-020-02578-7

Ho TY, Wu SL, Chen JC, Li CC, Hsiang CY (2007) Emodin blocks the SARS coronavirus spike protein and angiotensin-converting enzyme 2 interaction. Antivir Res 74(2):92-101. https://doi.org/10. 1016/j.antiviral.2006.04.014

Hussein OE, Hozayen WG, Bin-Jumah MN, Germoush MO, Abd E, Twab SM, Mahmoud AM (2020) Chicoric acid prevents methotrexate hepatotoxicity via attenuation of oxidative stress and inflammation and up-regulation of PPAR $\gamma$ and $\mathrm{Nrf} 2 / \mathrm{HO}-1$ signaling. Environ Sci Pollut Res :1-11. https://doi.org/10.1007/s11356-020-08557-y

Jin Z, Du X, Xu Y, Liu D, Zhao Y, Pen C (2020) Structure of M pro from SARS-CoV-2 and discovery of its inhibitors. Nature 582:289-293. https://doi.org/10.1038/s41586-020-2223-y

Jo S, Kim S, Shin DH, Kim MS (2020) Inhibition of SARS-CoV 3CL protease by flavonoids. J Enzyme Inhib Med Chem 35:145-151. https://doi.org/10.1080/14756366.2019.1690480

Kim JY, Kim YI, Park SJ, Kim IK, Choi YK, Kim SH (2018) Safe, highthroughput screening of natural compounds of MERS-CoV entry inhibitors using a pseudovirus expressing MERS-CoV spike protein. Int J Antimicrob Agents 52:730. https://doi.org/10.1016/j. ijantimicag.2018.05.003

Kiran G, Karthik L, Shree Devi MS, Sathiyarajeswaran P, Kanakavalli K, Kumar KM (2020) In silico computational screening of Kabasura Kudineer-official Siddha Formulation and JACOM against SARSCoV-2 spike protein. J Ayurveda Integr Med 25(20):S0975-S9476. https://doi.org/10.1016/j.jaim.2020.05.009

Lee WH, Loo CY, Bebawy M, Luk F, Mason RS, Rohanizadeh R (2013) Curcumin and its derivatives: their application in neuropharmacology and neuroscience in the 21 st century. Curr Neuropharmacol 1:338-378. https://doi.org/10.2174/ $1570159 X 11311040002$

Li F (2016) Structure, function, and evolution of coronavirus spike proteins. Ann Rev Virol 3:237-261. https://doi.org/10.1146/annurevvirology-110615-042301

Li W, Moore MJ, Vasilieva N, Sui J, Wong SK, Berne MA, Greenough TC (2003) Angiotensin-converting enzyme 2 is a functional receptor for the SARS coronavirus. Nature 426:450-454. https://doi.org/10. 1038/nature 02145

Li S, Chen C, Zhang H, Hy G, Wang H, Wang L, Xiao PG (2005) Identification of natural compounds with antiviral activities against SARS-associated coronavirus. Antivir Res 67:18-23. https://doi. org/10.1016/j.antiviral.2005.02.007

Li X, Jiang Q, Wang T, Liu J, Chen D (2016) Comparison of the antioxidant effects of quercitrin and isoquercitrin: Understanding the role of the 6 "-OH group. Molecules 21:1246. https://doi.org/ 10.3390/molecules21091246

Lima CF, Valentao PC, Andrade PB, Seabra RM, Fernandes-Ferreira M, Pereira-Wilson C (2007) Water and methanolic extracts of Salvia officinalis protect HepG2 cells from t-BHP induced oxidative damage. Chem Biol Interact 167:107-115. https://doi.org/10.1016/j.cbi. 2007.01.020

Lin WY, Yu YJ, Jinn TR (2019) Evaluation of the virucidal effects of rosmarinic acid against enterovirus 71 infection via in vitro and in vivo study. Virol J 16:94. https://doi.org/10.1186/s12985-019$1203-\mathrm{z}$ 
Mumivand H, Babalar M, Tabrizi L, Craker LE, Shokrpour M, Hadian J (2017) Antioxidant properties and principal phenolic phytochemicals of Iranian tarragon (Artemisia dracunculus L.) accessions. Hortic Environ Biotechnol 58:414-422. https://doi.org/10.1007/ s13580-017-0121-5

Nguyen TTH, Woo H-J, Kang H-K, Kim Y-M, Kim D-W, Ahn S-A, Kim D (2012) Flavonoid-mediated inhibition of SARS coronavirus 3C-like protease expressed in Pichia pastoris. Biotechnol Lett: 831838. https://doi.org/10.1007/s10529-011-0845-8

Nile SH, Kim DH, Nile A, Park GS, Gansukh E, Kai G (2020) Probing the effect of quercetin 3-glucoside from Dianthus superbus L against influenza virus infection In vitro and in silico biochemical and toxicological screening. Food Chem Toxicol 135:110985. https://doi. org/10.1016/j.fct.2019.110985

Pandey P, Rane JS, Chatterjee A, Kumar A, Khan R, Prakash A, Ray S (2020) Targeting SARS-CoV-2 spike protein of COVID-19 with naturally occurring phytochemicals: an in-silico study for drug development. J Biomol Struct Dyn :1-11. https://doi.org/10.1080/ 07391102.2020.1796811

Park J-Y, Yuk HJ, Ryu HW, Lim SH, Kim KS, Park KH, Lee WS (2017) Evaluation of polyphenols from Broussonetia papyrifera as coronavirus protease inhibitors. J Enzyme Inhib Med Chem 32:504-512. https://doi.org/10.1080/14756366.2016.1265519

Ryu YB, Jeong HJ, Kim JH, Kim YM, Park J-Y, Kim D, Park KH (2010) Biflavonoids from Torreya nucifera displaying SARS-CoV 3CLpro inhibition. Bioorg Med Chem 18:7940-7947. https://doi. org/10.1016/j.bmc.2010.09.035

Schwarz S, Wang K, Yu W, Sun B, Schwarz W (2011) Emodin inhibits current through SARS-associated coronavirus 3a protein. Antivir Res 90:64-69. https://doi.org/10.1016/j.antiviral.2011.02.008

Shang J, Zheng Y, Yang Y, Liu C, Geng Q, Tai W, Li F (2018) Cryoelectron microscopy structure of porcine delta-coronavirus spike protein in the prefusion state. J Virol 92:e01556-e01517. https:// doi.org/10.1128/JVI.01556-17

Shang J, Wan Y, Liu C, Yount B, Gully K, Yang Y, Li F (2020) Structure of mouse coronavirus spike protein complexed with receptor reveals mechanism for viral entry. PLoS Pathog 16:e1008392. https://doi.org/10.1371/journal.ppat.1008392

Shang J, Ye G, Shi K, Wan Y, Luo C, Aihara H, Li F (2020) Structural basis of receptor recognition by SARS-CoV-2. Nature 581:221224. https://doi.org/10.1038/s41586-020-2179-y

Sirois S, Zhang R, Gao W, Gao H, Li Y, Zheng H, Wei DQ (2007) Discovery of potent anti-SARS-CoV Mpro inhibitors. Curr Comput Aided Drug Des 3:191-200. https://doi.org/10.2174/ 157340907781695440

Song W, Gui M, Wang X, Xiang Y (2018) Cryo-EM structure of the SARS coronavirus spike glycoprotein in complex with its host cell receptor ACE2. PLoS Pathog 14:e1007236. https://doi.org/10.1371/ journal.ppat.1007236

Tajik N, Tajik M, Mack I, Enck P (2017) The potential effects of chlorogenic acid, the main phenolic components in coffee, on health: a comprehensive review of the literature. Eur J Nutr 56: 2215-2244. https://doi.org/10.1007/s00394-017-1379-1

Thiel V, Herold J, Schelle B, Siddell SG (2001) Viral replicase gene products suffice for coronavirus discontinuous transcription. J Virology 75:6676-6681. https://doi.org/10.1128/JVI.75.14.66766681.2001

Vasavi H, Sudeep H, Lingaraju H, Prasad KS (2017) Bioavailabilityenhanced Resveramax ${ }^{\mathrm{TM}}$ modulates quorum sensing and inhibits biofilm formation in Pseudomonas aeruginosa PAO1. Microb Pathog 104:64-71. https://doi.org/10.1016/j.micpath.2017.01.015

Voysey M, Clemens SAC, Madhi SA, Weckx LY, Folegatti PM, Aley PK, Bhorat QE (2020) Safety and efficacy of the ChAdOx1 nCoV19 vaccine (AZD1222) against SARS-CoV-2: an interim analysis of four randomized controlled trials in Brazil, South Africa, and the UK. The Lancet 397:99-111. https://doi.org/10.1016/S0140-6736 (20)32661-1

Walls AC, Tortorici MA, Bosch B-J, Frenz B, Rottier PJ, DiMaio F, Veesler D (2016) Cryo-electron microscopy structure of a coronavirus spike glycoprotein trimer. Nature 531:114-117. https://doi. org/10.1038/nature 16988

Walls AC, Tortorici MA, Snijder J, Xiong X, Bosch B-J, Rey FA, Veesler D (2017) Tectonic conformational changes of a coronavirus spike glycoprotein promote membrane fusion. Proceedings of the National Academy of Sciences 114: 11157-11162. https://doi.org/ 10.1073/pnas. 1708727114

Wen C-C, Kuo Y-H, Jan J-T, Liang P-H, Wang S-Y, Liu H-G, Lee SS (2007) Specific plant terpenoids and lignoids possess potent antiviral activities against severe acute respiratory syndrome coronavirus. J Med Chem 50:4087-4095. https://doi.org/10.1021/jm070295s

WHO organization (2021) Weekly epidemiological update on COVID19 - 29 June. Edition 46.

Wrapp D, Wang N, Corbett KS, Goldsmith JA, Hsieh C-L, Abiona O, McLellan JS (2020) Cryo-EM structure of the 2019-nCoV spike in the prefusion conformation. Science 367:1260-1263. https://doi. org/10.1126/science.abb2507

Wu CY, Jan JT, Ma SH, Kuo CJ, Jua HF, Cheng YSE, Hsu HH, Huang HC, Wu D, Brik A, Liang FS, Liu RS, Fang JM, Chen ST, Liang PH, Wong CH (2004) Small molecules targeting severe acute respiratory syndrome human coronavirus. Proc Natl Acad Sci USA 101: 10012-10017. https://doi.org/10.1073/pnas.0403596101

Wu Q, Kroon PA, Shao H, Needs PW, Yang X (2018) Differential effects of quercetin and two of its derivatives, isorhamnetin and isorhamnetin-3-glucuronide, in inhibiting the proliferation of human breast cancer MCF-7 cells. J Agric Food Chem 66:7181-7189. https://doi.org/10.1021/acs.jafc.8b02420

Yi L, Li Z, Yuan K, Qu X, Chen J, Wang G, Jiang P (2004) Small molecules blocking the entry of severe acute respiratory syndrome coronavirus into host cells. J Virology 78:11334-11339. https://doi. org/10.1128/JVI.78.20.11334-11339.2004

Yu R, Chen L, Lan R, Shen R, Li P (2020) Computational screening of antagonist against the SARS-CoV-2 (COVID-19) coronavirus by molecular docking. Int J of Ant Agents 56(2):106012. https://doi. org/10.1016/j.jjantimicag.2020.106012

Zhang DH, Wu KL, Zhang X, Deng SQ, Peng B (2020) In silico screening of Chinese herbal medicines with the potential to directly inhibit 2019 novel coronavirus. J Integr Med 18:152-158. https:// doi.org/10.1016/j.joim.2020.02.005

Zhu N, Zhang D, Wang W, Li X, Yang B, Song J, Lu R (2020) A novel coronavirus from patients with pneumonia in China, 2019. N Engl J Med 382:727-733. https://doi.org/10.1056/NEJMoa2001017

Ziebuhr J, Herold J, Siddell SG (1995) Characterization of a human coronavirus (strain 229E) 3C-like proteinase activity. J Virology 69: 4331-4338. https://doi.org/10.1128/jvi.69.7.4331-4338.1995

Publisher's Note Springer Nature remains neutral with regard to jurisdictional claims in published maps and institutional affiliations. 